NBER WORKING PAPER SERIES

\title{
MANAGING CREDIT BOOMS AND BUSTS: A PIGOUVIAN TAXATION APPROACH
}

\author{
Olivier Jeanne \\ Anton Korinek \\ Working Paper 16377 \\ http://www.nber.org/papers/w16377
NATIONAL BUREAU OF ECONOMIC RESEARCH
1050 Massachusetts Avenue
Cambridge, MA 02138
September 2010

The authors would like to thank David Cook, C. Bora Durdu, Enrique Mendoza, Raoul Minetti, Joseph Stiglitz and Dimitri Vayanos as well as participants at seminars at the FRB and at JHU and at the Dallas Fed/Bank of Canada conference on Capital Flows, an IMF Workshop on Systemic Risk, the 2nd Tilburg Financial Stability Conference and the Paul Woolley Conference on Capital Market Dysfunctionality for helpful comments and suggestions. Financial support from the Europlace Institute of Finance is gratefully acknowledged. The views expressed herein are those of the authors and do not necessarily reflect the views of the National Bureau of Economic Research.

NBER working papers are circulated for discussion and comment purposes. They have not been peerreviewed or been subject to the review by the NBER Board of Directors that accompanies official NBER publications.

(C) 2010 by Olivier Jeanne and Anton Korinek. All rights reserved. Short sections of text, not to exceed two paragraphs, may be quoted without explicit permission provided that full credit, including $\odot$ notice, is given to the source. 
Managing Credit Booms and Busts: A Pigouvian Taxation Approach

Olivier Jeanne and Anton Korinek

NBER Working Paper No. 16377

September 2010

JEL No. E44,G38

\begin{abstract}
$\underline{\text { ABSTRACT }}$
We study a dynamic model in which the interaction between debt accumulation and asset prices magnifies credit booms and busts. We find that borrowers do not internalize these feedback effects and therefore suffer from excessively large booms and busts in both credit flows and asset prices. We show that a Pigouvian tax on borrowing may induce borrowers to internalize these externalities and increase welfare. We calibrate the model by reference to (i) the US small and medium-sized enterprise sector and (ii) the household sector, and find the optimal tax to be countercyclical in both cases, dropping to zero in busts and rising to approximately half a percentage point of the amount of debt outstanding during booms.
\end{abstract}

Olivier Jeanne

Department of Economics

Johns Hopkins University

454 Mergenthaler Hall

3400 N. Charles Street

Baltimore, MD 21218

and NBER

ojeanne@jhu.edu

Anton Korinek

University of Maryland

Tydings Hall 4118F

College Park, MD 20742

akorinek@umd.edu 


\section{Introduction}

The interaction between debt accumulation and asset prices contributes to magnify the impact of booms and busts. Increases in borrowing and in collateral prices feed each other during booms. In busts, the feedback turns negative, with credit constraints leading to fire sales of assets and further tightening of credit. It has been suggested that prudential policies could be used to mitigate the build-up in systemic vulnerability during the boom. However, there are few formal welfare analyses of the optimal policies to deal with booms and busts in credit and asset prices.

This paper makes a step toward filling this gap with a dynamic optimizing model of collateralized borrowing. We consider a group of individuals (the insiders) who enjoy a comparative advantage in holding an asset and who can use this asset as collateral on their borrowing from outsiders. The borrowing capacity of insiders is therefore increasing in the price of the asset. The price of the asset, in turn, is driven by the insiders' consumption and borrowing capacity. This introduces a mutual feedback loop between asset prices and credit flows: small financial shocks to insiders can lead to large simultaneous booms or busts in asset prices and credit flows.

The model attempts to capture, in a stylized way, a number of economic settings in which the systemic interaction between credit and asset prices may be important. The insiders could be interpreted as a group of entrepreneurs who have more expertise than outsiders to operate a productive asset, or as households putting a premium on owning durable consumer assets or their homes. Alternatively, insiders could represent a group of investors who enjoy an advantage in dealing with a certain class of financial assets, for example because of superior information or superior risk management skills. One advantage of studying these situations with a common framework is to bring out the commonality of the problems and of the required policy responses although, in the real world, those policies pertain to different areas such as financial regulation, or individual and corporate taxation.

One of our main results is that the asset-debt loop entails systemic externalities that lead borrowers to undervalue the benefits of conserving liquidity as a precaution against busts. A borrower who has one more dollar of liquid net worth when the economy experiences a bust relaxes not only his private borrowing constraint but also the borrowing constraints of all other insiders. Not internalizing this spillover effect, the insider takes on too much debt during good times. We find that it would be optimal to impose a cyclical tax 
on borrowing by leveraged insiders to prevent them from taking on socially excessive debt.

It is important that the level of the tax on a given sector be adjusted to its vulnerability to credit and asset price busts. In a benchmark calibration of our model to the US small and medium-sized enterprise (SME) sector, we find that the optimal tax converges to 0.56 percent of the amount of debt outstanding over the course of a boom, and drops to zero when a bust occurs. Borrowing by the US household sector is subject to externalities of similar magnitude (0.48 percent in booms). By contrast, US Flow of Funds data over the past decade suggest that large corporations who have access to corporate bond markets were less subject to systemic externalities and did not require macro-prudential measures.

We study four extensions of the basic model and find that its essential properties are preserved. First, we change the nature of the shock by assuming that it affects the availability of credit rather than the income of insiders. Then we look at the case where insiders can issue long-term debt or equity. All three of these extensions change some features of the boom-bust cycle equilibrium, but it remains true that the constrained optimum can be achieved by a countercyclical tax on debt, and this tax is of the same order of magnitude as in the benchmark model. Finally, we compare ex ante prudential taxation to ex post interventions that provide funds to constrained borrowers in a bust. We find that a bailout insurance fund that accumulates resources in good times and transfers them to debtors in a bust does not increase welfare (unless the resources are levied through the optimal Pigouvian $\operatorname{tax})$.

Our model is related to the positive study of financial accelerator effects in closed and open economy macroeconomics. In closed-economy DSGE models, Carlstrom and Fuerst (1997) and Bernanke, Gertler and Gilchrist (1999) show that financial frictions amplify the response of an economy to fundamental shocks. However, models in this literature are traditionally solved by linearization, making them more appropriate to analyze regular business cycle fluctuations than systemic crises. In the open economy literature, Mendoza (2005) and Mendoza and Smith (2006), among others, have studied the non-linear dynamics arising from financial accelerator effects during sudden stops in emerging market economies. Mendoza (2010) focuses on the positive implications of such dynamics in a framework with asset prices.

Benigno et al (2009) and Bianchi (2009) characterize welfare-maximizing policies in such models. Their papers focus on the role of exchange rate 
depreciations in emerging market crises and find an externality that involves the real exchange rate rather than the price of a domestic asset. By contrast, our model does not have an exchange rate and attempts to capture the essence of the problem in a generic setting involving asset price deflation. Bianchi and Mendoza (2010) analyze a similar externality mechanism for the aggregate US economy but focus on the implications of credit constraints on labor demand, whereas we emphasize the necessity to differentiate policy measures by the vulnerability of each sector in the economy.

Our paper is also related to analyses of the ongoing world-wide credit crisis that emphasize the amplifying mechanisms involving asset price deflation and deleveraging in the financial sector (e.g., Adrian and Shin, 2009; Brunnermeier, 2009). Some earlier contributions have clarified the externalities involved in credit booms and busts and drawn some implications for policy in the context of stylized two- or three-period models (Caballero and Krishnamurthy, 2003; Lorenzoni, 2008; Korinek, 2009, 2010; Jeanne and Korinek, 2010). By contrast, this paper gives a more realistic and quantitative flavor to the analysis, by considering an infinite-horizon model. This allows us to study macroprudential policies over booms and busts and is particularly relevant for determining the optimal magnitude of regulatory measures in practice.

Finally, our paper presents a numerical solution method for DSGE models with occasionally binding endogenous constraints that extends the endogenous gridpoints method of Carroll (2006). This method allows us to solve such models in an efficient way and may enable researchers to analyze more complex models than what has been computationally feasible in the existing DSGE literature with endogenous constraints, ultimately producing policy guidance on richer and more realistic models of the economy.

The structure of the paper is as follows. Section 2 presents the assumptions of the model. Section 3 compares the laissez-faire equilibrium with a social planner. Section 4 presents a calibration of our model and explores its quantitative implications. Section 5 discusses extensions of the benchmark model, and section 6 concludes.

\section{The model}

We consider a group of identical atomistic individuals in infinite discrete time $t=0,1,2, \ldots$. The individuals are indexed by $i \in[0,1]$. The utility of 
individual $i$ at time $t$ is given by,

$$
U_{i, t}=E_{t}\left(\sum_{s=t}^{+\infty} \beta^{s-t} u\left(c_{i, s}\right)\right),
$$

where $u(\cdot)$ is strictly concave and satisfies the Inada conditions. We will generally assume that utility has constant relative risk aversion,

$$
u(c)=\frac{c^{1-\gamma}}{1-\gamma}
$$

These individuals (the insiders) receive two kinds of income, the payoff of an asset that can serve as collateral, and an endowment income. Insider $i$ maximizes his utility under the budget constraint

$$
c_{i, t}+a_{i, t+1} p_{t}+\frac{w_{i, t+1}}{R}=(1-\alpha) y_{t}+a_{i, t}\left(p_{t}+\alpha y_{t}\right)+w_{i, t}
$$

where $a_{i, t}$ is the insider's holdings of the collateral asset at the beginning of period $t$ and $p_{t}$ is its price; $w_{i, t}$ is the individual's wealth at the start of period $t ; y_{t}$ is total income in period $t$ (the same for all individuals) and $\alpha y_{t}$ is the share of that income that comes from the asset. For example, if the collateral asset were productive capital used in a Cobb-Douglas production function, and labor were provided by outsiders, $\alpha$ would be the exponent of capital in the production function. Wealth is invested with outside investors who have an indefinite demand/supply for risk-free bonds at the safe interest rate $r=R-1$. Wealth may be negative, in which case insiders sell debt to outside investors.

Total income $y_{t}$ follows a stochastic process which, for the sake of simplicity, we will assume to be identically and independently distributed, although it would be straightforward to extend the analysis to the case where it is Markov. ${ }^{1}$ Assuming an i.i.d. process for $y_{t}$ is not too restrictive given that, in the calibration, we will consider shocks that represent rare crises rather than business cycle fluctuations. ${ }^{2}$

The collateral asset is not reproducible and the available stock of asset is normalized to 1 . The asset can be exchanged between insiders in a perfectly

\footnotetext{
${ }^{1}$ The only difference, in the Markov case, is that the policy functions will also depend on the current level of $y$ in addition to the level of wealth $w$.

${ }^{2}$ We could also introduce growth into the model. The model with growth, once detrended, would be isomorphic to the model presented here.
} 
competitive market, but cannot be sold to outsiders: $a_{i, t}$ must be equal to 1 in a symmetric equilibrium where all insiders behave in the same way. We do not allow insiders to sell the asset to outsiders and rent it back because insiders derive benefits from the control rights that ownership provides. This restriction could be relaxed to some extent, but we need a restriction of this form for insiders to issue collateralized debt.

Furthermore, we assume that the only financial instrument that can be traded between insiders and outsiders is uncontingent one period debt. This assumption can be justified e.g. on the basis that shocks to the insider sector are not verifiable and cannot be used to condition payments, and that short-term debt provides insiders with adequate incentives. This feature corresponds to common practice across a wide range of financial relationships. ${ }^{3}$

After rolling over his debt in period $t$, we assume that the representative insider faces a moral hazard problem: he has the option to invest in a scam that allows him to remove his future asset and endowment income from the reach of his current creditors. This would allow him to default on his debts next period without facing a penalty.

We assume that outsiders cannot coordinate to punish the agent by excluding him from borrowing in future periods. However, they can observe the scam in the current period and take the insider to court before the scam is completed. If they do so, they can seize a quantity of good $\psi$ plus a fraction $\phi<1$ of the insider's asset, where the inequality captures imperfect legal enforcement. Since the asset cannot be held by outsiders, they re-sell them to other insiders at the prevailing market price $p_{t}$. This implies the following incentive compatibility constraint for insiders to refrain from the scam:

$$
\frac{w_{i, t+1}}{R}+\psi+\phi p_{t} \geq 0
$$

This constraint is similar to that in Kiyotaki and Moore (1997). The value of the collateral asset determines how much debt insiders are able to roll over. We assume that subject to this constraint, debt issued in period $t$ is repaid with certainty in period $t+1$.

Constraint (3) could be specified in different ways. For example, it could involve a fraction of the collateral asset held by the borrower at the beginning or the end of the period, or be a nonlinear increasing function of $p_{t}$. The only

\footnotetext{
${ }^{3}$ More generally, the findings of Korinek (2010) suggest that our results on excessive exposure to binding constraints would continue to hold when insiders have access to costly state-contingent financial contracts.
} 
important assumption, to obtain the debt-asset deflation mechanism at the core of the model, is that the credit constraint depends on the current-period market price of the asset, $p_{t}{ }^{4}$

\section{Laissez-faire vs. Social Planner}

We characterize the symmetric laissez-faire equilibrium and compare it to the social planner solution. First, we derive the equilibrium conditions (section 3.1). We then present some considerations on equilibrium multiplicity and the possibility of self-fulfilling asset price and debt busts (section 3.2). Finally, section 3.3 focuses on the case where saving is determined by a social planner.

\subsection{Equilibrium conditions under laissez-faire}

We derive in the appendix the first-order conditions for the optimization problem of an insider $i$. We then use the fact that in a symmetric equilibrium, all individuals are identical and hold one unit of collateral asset $\left(\forall i, t \quad a_{i, t}=\right.$ 1). Variables without the subscript $i$ refer to the representative insider (or equivalently, to aggregate levels, since the mass of insiders is normalized to 1). This gives the following two conditions

$$
\begin{gathered}
u^{\prime}\left(c_{t}\right)=\lambda_{t}+\beta R E_{t}\left[u^{\prime}\left(c_{t+1}\right)\right], \\
p_{t}=\beta \frac{E_{t}\left[u^{\prime}\left(c_{t+1}\right)\left(\alpha y_{t+1}+p_{t+1}\right)\right]}{u^{\prime}\left(c_{t}\right)},
\end{gathered}
$$

\footnotetext{
${ }^{4}$ In our simple setup of an endowment economy, financial amplification dynamics do not arise if the constraint depends solely on future asset prices: an exogenous tightening of the constraint would reduce borrowing today and lead to increased future wealth and higher future consumption, which raises the level of future asset prices, thereby relaxing the constraint, leading to financial deceleration. In a model such as Kiyotaki and Moore (1997) that includes investment in capital and a complementary asset in fixed supply (land), financial amplification also arises with a constraint involving future asset prices $\phi a_{i, t+1} p_{t+1}$ : an exogenous tightening of the constraint would reduce current capital investment, making complementary land less valuable in the future and therefore reducing its price, which in turn tightens the constraint further. However, adding investment as an additional endogenous state variable to our nonlinear stochastic model setup would increase the computational burden by an order of magnitude.
} 
where $\lambda_{t}$ is the costate variable for the borrowing constraint. The first equation is the Euler condition and the second one is the standard asset pricing equation.

The equilibrium is characterized by a set of functions mapping the state of the economy into the endogenous variables. Given that $y_{t}$ is i.i.d., we can summarize the state by one variable, the beginning-of-period liquid net wealth excluding the value of the collateral asset,

$$
m_{t} \equiv y_{t}+w_{t}
$$

We do not include the asset in the definition of net wealth because its price, $p_{t}$, is an endogenous variable. In a symmetric equilibrium the budget constraint (2) simplifies to

$$
c_{t}+\frac{w_{t+1}}{R}=y_{t}+w_{t},
$$

and the collateral constraint (3) can be written, in aggregate form,

$$
c_{t} \leq m_{t}+\psi+\phi p_{t}
$$

The equilibrium, thus, is characterized by three non-negative functions, $c(m), p(m)$ and $\lambda(m)$ such that

$$
\begin{gathered}
c(m)=\min \left\{m+\psi+\phi p(m),\left[\beta R E\left(c\left(m^{\prime}\right)^{-\gamma}\right)\right]^{-1 / \gamma}\right\}, \\
\lambda(m)=c(m)^{-\gamma}-\beta R E\left(c\left(m^{\prime}\right)^{-\gamma}\right), \\
p(m)=\beta E\left[c\left(m^{\prime}\right)^{-\gamma}\left(\alpha y^{\prime}+p\left(m^{\prime}\right)\right)\right] c(m)^{\gamma},
\end{gathered}
$$

where next-period values are denoted with primes. The transition equation for net wealth is

$$
m^{\prime}=y^{\prime}+R(m-c(m))
$$

\subsection{Multiple equilibria}

Many papers, in the dynamic optimization literature on consumption and saving, compute the equilibrium policy functions by iterating on the firstorder conditions, under the assumption that this method converges towards 
policy functions that exist and are unique. ${ }^{5}$ However, we cannot make such an assumption here as our model generically gives rise to equilibrium multiplicity. We give in this section a heuristic account of the mechanism underlying multiplicity and of the conditions that ensure uniqueness. ${ }^{6}$

The multiplicity comes from the self-reinforcing loop that links consumption to the price of the collateral. In the constrained regime, a fall in the price of the collateral asset decreases the insiders' level of consumption, which in turn tends to depress the price of the asset. This loop, which is essential for our results since it explains the financial magnification of real shocks, may also - if its effect is strong enough-lead to self-fulfilling crashes in the price of the asset.

More formally, the loop linking consumption to the asset price is captured by equations (5) and (7). Assuming that the policy functions $c(m), p(m)$ and $\lambda(m)$ apply in the following period, equation (5) implicitly defines the asset price as a function of the state and of current consumption,

$$
\hat{p}(m, c)=\beta E\left[u^{\prime}\left(c\left(m^{\prime}\right)\right)\left(\alpha y^{\prime}+p\left(m^{\prime}\right)\right)\right] c^{\gamma},
$$

where the expectation is taken conditional on $m$ and $c$, with $m^{\prime}=y^{\prime}+$ $R(m-c)$. The credit constraint $(7)$ can then be written

$$
c \leq m+\psi+\phi \hat{p}(m, c)
$$

The right-hand side of (13) is increasing in $c$ because the credit constraint on each individual is relaxed by a higher level of aggregate consumption that raises the price of the asset. ${ }^{7}$ Multiplicity may arise if the left-hand side and the right-hand side of (13) intersect for more than one level of $c$.

We further explore the multiplicity of equilibria in the remainder of this section by considering a special case of the model that can be solved (almost

\footnotetext{
${ }^{5}$ See Zeldes (1989) for an early example. Stokey et al (1989) present several fixedpoint theorems guaranteeing that the equilibrium exists, is unique, and can be obtained by iterating on the problem's first-order conditions. However, the models considered in most of the literature (including Zeldes') do not satisfy the conditions under which those theorems are applicable - see the discussion in Carroll (2008).

${ }^{6} \mathrm{We}$ are not aware of papers giving general conditions under which the equilibrium is unique in models of the type considered here (i.e., extensions of Carroll's (2008) analysis to the case with endogenous credit constaints).

${ }^{7}$ This is captured by the factor $c^{\gamma}$ on the r.h.s. of (12). However, because of the other terms in $m^{\prime}$, the sign of the variations of $\hat{p}$ with $c$ is a priori ambiguous.
} 
completely) in closed form: the case where $y$ is constant and $\beta R=1$. We summarize the main results below (the details can be found in the appendix).

We derive the equilibrium for $t=1,2 \ldots$ starting from an initial level of wealth $m_{1}$. It is easy to show that from period 2 onwards, the economy is in an unconstrained steady state in which the price of the asset is given by

$$
p^{u n c}=\frac{\alpha y}{r} .
$$

The economy is constrained in period 1 if and only if the initial level of net wealth is lower than a threshold $\bar{m}$. The function $\hat{p}(\cdot, \cdot)$ in period 1 is given by

$$
\hat{p}\left(m_{1}, c_{1}\right)=p^{u n c} \cdot \min \left\{\left(\frac{c_{1}}{y+r\left(m_{1}-c_{1}\right)}\right)^{\gamma}, 1\right\} .
$$

Figure 1 illustrates the case with multiple equilibria by showing the variations of both sides of (13) with $c_{1}$. The unconstrained equilibrium (point $A$ ) coexists with a constrained equilibrium featuring lower levels for consumption and the asset price (point $C$ ) ${ }^{8}$ The multiplicity comes from the fact that the slope of the r.h.s. of (13) is larger than 1 over some range. Then a one-dollar fall in aggregate consumption tightens the credit constraint by more than one dollar for each individual, allowing a self-fulfilling downward spiral in consumption and the price of the asset.

As shown in the appendix, the equilibrium is unique if and only if $\phi$ is small enough,

$$
\phi \leq \frac{y-r \psi}{\alpha y\left[\left(1+\frac{1}{r}\right) \gamma+1\right]}
$$

For the parameter values used to construct Figure 1, for example, equilibrium uniqueness is ensured by taking $\phi \leq 0.089$. A small $\phi$ contains the strength of the amplification effects below the level where it leads to multiple equilibria.

Equilibrium multiplicity, as we will show in section 4.2 , is likely to be relevant for highly-leveraged institutions in the financial sector. However, it

\footnotetext{
${ }^{8}$ The figure was constructed by giving parameters $R, \gamma, \alpha$, and $\psi$ the same values as in our benchmark calibration (given in Table 1). In addition we took $y=1, m_{1}=-1.3$ and $\phi=0.2$. There is one more intersection (point $B$ ) between $A$ and $C$. However, point $B$ corresponds to an unstable equilibrium in the sense that a one dollar change in aggregate consumption changes the maximum level of individual consumption by more than one dollar, so that the economy would tip toward points $A$ or $C$ following a small perturbation in consumption.
} 


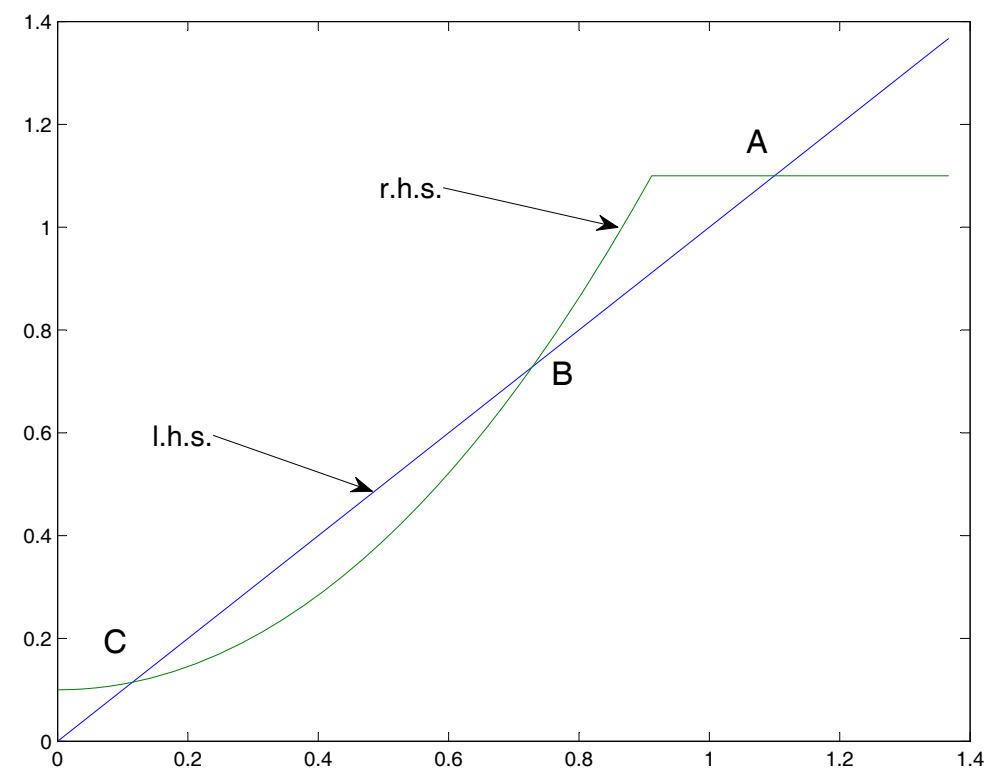

Figure 1: L.h.s. and r.h.s. of equation (13) ( $y$ constant and $\beta R=1$ )

raises a number of issues (in particular, how the equilibrium is selected) that we prefer to leave aside for now. We will thus ensure that the equilibrium is unique by assuming sufficiently low values of $\phi$.

\subsection{Social planner}

We assume that the social planner of the economy determines the amount of insiders' borrowing, but does not directly interfere in asset markets - that is, the social planner takes as given that insiders trade the collateralizable asset at a price that is determined by their private optimality condition (5). The social optimum differs from the laissez-faire equilibrium because the social planner internalizes that future asset prices and insiders' borrowing capacity depend on the aggregate level of debt accumulated by insiders. A possible motivation for this setup is that decentralized agents are better than the planner at observing the fundamental payoffs of financial assets, while only the social planner has the capacity of internalizing the costs of debt deflation dynamics that may arise from high levels of debt. 
In period $t$, the social planner chooses the wealth level of the representative insider, $w_{t+1}$, before the asset market opens at time $t$. The asset market remains perfectly competitive, i.e., individual market participants optimize on $a_{t+1}$ subject to their budget constraints. We look for time-consistent equilibria in which the social planner optimizes on $w_{t+1}$ taking the future policy functions $c(m)$ and $p(m)$ as given. (Although we do not change the notation, those policy functions are not the same as in the laissez-faire equilibrium.)

Through savings, the social planner determines the price of the asset, which at time $t$ is given by

$$
p_{t}=\hat{p}\left(m_{t}, m_{t}-w_{t+1} / R\right)
$$

where the function $\hat{p}(\cdot, \cdot)$ is given by equation $(12)$.

Since insiders are still subject to the collateral constraint (3), the social planner sets $w^{\prime}$ subject to

$$
\frac{w^{\prime}}{R}+\psi+\phi \hat{p}\left(m, m-w^{\prime} / R\right) \geq 0
$$

If $\phi$ is small enough to avoid multiple equilibria (as we have assumed), the left-hand side increases with $w^{\prime}$, so that this inequality determines a lower bound on aggregate wealth (i.e., an upper bound on aggregate debt). Then the social planner's credit constraint can be rewritten in reduced form,

$$
\frac{w^{\prime}}{R}+\psi+\phi \bar{p}(m) \geq 0
$$

where $\bar{p}(m)$ is the level of $p\left(m, m-w^{\prime} / R\right)$ for which (17) is an equality. Note that by definition, we have $\bar{p}(m)=p(m)$ for all the levels of $m$ in which the social planner's constraint is binding.

The social planner solves the same optimization problem as decentralized agents, except that he takes $a_{t}=1$ as given in the aggregate budget constraint, and that his credit constraint is given by (18). As shown in the appendix, the social planner's Euler equation is,

$$
u^{\prime}\left(c_{t}\right)=\lambda_{t}+\beta R E_{t}\left(u^{\prime}\left(c_{t+1}\right)+\lambda_{t+1} \phi \bar{p}^{\prime}\left(m_{t+1}\right)\right) .
$$

By comparing (4) and (19) and noting that $\bar{p}^{\prime}\left(m_{t+1}\right)>0$, one can see that the social planner raises saving above the laissez-faire level if there is a risk of binding financial constraints next period $E_{t} \lambda_{t+1}>0$. The planner's wedge 
is proportional to the expected product of the shadow cost of the credit constraint times the derivative of the debt ceiling with respect to wealth. This reflects that the social planner internalizes the endogeneity of next period's asset price and credit constraint to this period's aggregate saving.

With the social planner, precautionary savings is augmented by a systemic component - the social planner implements a policy of macro-prudential saving. This does not come from the fact that the central planner estimates risks better than individuals. Decentralized agents are aware of the risk of credit crunch and maintain a certain amount of precautionary saving (they issue less debt than if this risk were absent). But they do not internalize the contribution of their precautionary savings to reducing the systemic risk coming from the debt-asset deflation spiral.

The social planner's Euler equation also provides guidance for how the socially optimal equilibrium can be implemented via taxes on borrowing. Decentralized agents undervalue the social cost of debt by the term $\phi E_{t}\left[\lambda_{t+1} p^{\prime}\left(m_{t+1}\right)\right]$ on the right-hand side of the social planner's Euler equation (19), which depends on the level of wealth $m_{t}$. The planner's equilibrium can be implemented by a Pigouvian tax $\tau_{t}=\tau\left(m_{t}\right)$ on borrowing that is rebated as a lump sum transfer $T_{t}=-\tau_{t} w_{t+1} / R$ :

$$
c_{t}=y_{t}+w_{t}-\frac{w_{t+1}}{R}\left(1-\tau_{t}\right)+T_{t} .
$$

The tax introduces a wedge in the insiders' Euler equation,

$$
\left(1-\tau_{t}\right) u^{\prime}\left(c_{t}\right)=\lambda_{t}+\beta R E_{t}\left[u^{\prime}\left(c_{t+1}\right)\right],
$$

and replicates the constrained social optimum if it is set to

$$
\tau\left(m_{t}\right)=\frac{\phi \beta R E_{t}\left[\lambda_{t+1} \bar{p}^{\prime}\left(m_{t+1}\right)\right]}{u^{\prime}\left(c_{t}\right)},
$$

where all variables are evaluated at the social optimum.

The tax raises saving only if the economy is unconstrained under the social planner so that consumption allocations are determined by the Euler equation of insiders. If the economy is constrained, consumption and saving are determined by the binding constraint. As a result, the social planner equilibrium is unchanged if we lower $\tau(m)$ to zero in constrained states $m$ where $\lambda(m)>0$. 


\section{Quantitative Exploration}

We now turn the attention to the quantitative implications of the model. Sections 4.1 and 4.2 respectively present our numerical resolution method and our calibration. Section 4.3 discusses the results of a numerical simulation with booms and busts in the asset price and in credit flows. The last section presents some sensitivity analysis.

\subsection{Numerical resolution}

In order to generate a persistent motive for borrowing, we need to assume that insiders are impatient relative to outsiders, i.e., ${ }^{9}$

$$
\beta R<1
$$

We can make conjectures about the form of the solution by analogy with the deterministic case studied in the previous section. We consider equilibria that are unique and in which the consumption function $m \mapsto c(m)$ is a continuously increasing function of wealth. Let us denote by $\underline{m}$ the level of wealth for which consumption is equal to zero,

$$
c(\underline{m})=0 .
$$

By analogy with the deterministic case, we would expect the insiders to be credit-constrained in a wealth interval $m \in[\underline{m}, \bar{m}]$, and to be unconstrained for $m \geq \bar{m}$. It is not difficult to see that the lower threshold must be equal to

$$
\underline{m}=-\psi \text {. }
$$

This results from the facts that $c(m) \leq m+\psi+\phi p$, and that $p$ converges to zero as $c$ goes to zero (by equation (5)). Since $m=y+w$ must be larger than $-\psi$ and the level of $w$ is set before the realization of $y$, we must also have

$$
w+\psi+\min y \geq 0 .
$$

The upper threshold, $\bar{m}$, above which insiders are unconstrained must be determined numerically.

\footnotetext{
${ }^{9}$ With trend growth at a growth factor $G$, we could allow $\beta R \geq 1$ as long as $\beta R G^{1-\gamma}<$ 1.
} 
The numerical resolution method is an extension of the endogenous grid points method of Carroll (2006) to the case where the credit constraint is endogenous. The procedure performs backwards time iteration on the agent's optimality conditions. We define a grid $\mathbf{w}$ for next period wealth levels $w^{\prime}$ and combine the next period policy functions with agent's optimality conditions to obtain current period policy functions until the resulting functions converge. The difference with Carroll (2006) is that the threshold level at which the borrowing constraint becomes binding is endogenous. This implies that the minimum level of wealth is itself a function of the state, which is obtained by iterating on the asset pricing equation (10). The details of the numerical resolution method are provided in the appendix.

\subsection{Calibration}

We assume that the process for income is binomial: total income is high (equal to $y_{H}$ ) with probability $1-\pi$, or low (equal to $y_{L}$ ) with probability $\pi$. The high state is the normal state that prevails most of the time, whereas the realization of the low state is associated with a bust in the asset price and in credit, which occurs infrequently. Thus, we calibrate our model by reference to rare and large events rather than real business cycle fluctuations. We will assume that a bust occurs once every twenty years on average.

Our benchmark calibration is reported in Table 1 . The riskless real interest rate is set to 3 percent. The discount factor is set to 0.96 , a value that is low enough to induce the insiders to borrow and expose themselves to the risk of a credit crunch. The risk aversion parameter is equal to 2 , a standard value in the literature.

Table 1. Benchmark calibration

\begin{tabular}{ccccccccc}
$\beta$ & $R$ & $\gamma$ & $\alpha$ & $y_{L}$ & $y_{H}$ & $\pi$ & $\phi$ & $\psi$ \\
\hline 0.96 & 1.03 & 2 & 0.2 & 0.969 & 1 & 0.05 & 0.046 & 1.97
\end{tabular}

The other parameters have been calibrated by reference to the experience of the US small and medium enterprises (SMEs) in 2008-09. We have also looked at other US sectors (the household sector and the nonfinancial corporate sector) in order to obtain plausible ranges of variation for the parameters. We discuss the case of the US financial sector at the end of this section. 
The relevant data for the US nonfinancial sectors are shown in Table $2{ }^{10}$ For each sector we report the change in the value of assets and the change in debt during a one-year time window centered on the peak of the crisis (the fall of 2008). For households and SMEs we observe that the value of assets and debt both fall, consistent with the model. Corporations also had a fall in asset value but they were able to slightly increase their outstanding debt by issuing larger amounts of corporate bonds, in spite of a contraction in bank lending. The difference between SMEs and the corporate business sector, thus, is consistent with the notion that the former are more vulnerable than the latter to a credit crunch because they are more dependent on bank lending.

\section{Table 2. Balance sheet data for US Households, SMEs and Corporations (in \$bn)}

\begin{tabular}{l|l|l|l|l|l|l|} 
& \multicolumn{3}{|c|}{ Assets } & \multicolumn{3}{c|}{ Debt } \\
& 2008Q2 & 2009Q2 & Chg. & 2008Q2 & 2009Q2 & Chg. \\
\hline Households & 74,273 & 64,425 & $-13.3 \%$ & 14,418 & 14,116 & $-2.1 \%$ \\
SMEs & 11,865 & 10,409 & $-12.3 \%$ & 5,410 & 5,343 & $-1.2 \%$ \\
Corporations & 28,579 & 26,521 & $-7.2 \%$ & 13,039 & 13,597 & $+4.3 \%$
\end{tabular}

Table 3 shows our calibration of $\alpha, \phi, \psi$, and $y_{L}$ for the three sectors covered by Table 2 except US corporations. We do not include the US corporate sector because, as mentioned above, its outstanding debt did not fall during the crisis.

The share of the asset in income, $\alpha$, was inferred from the ratio of the asset price to total income. Abstracting from the risk of bust, the price of

\footnotetext{
${ }^{10}$ The source is the Federal Reserve's Flow of Funds database. The data for Households, SMEs and Corporations respectively come from Table B.100 (Households and Nonprofit Organizations), Table B.102 (Nonfarm Nonfinancial Corporate Business) and Table B.103 (Nonfarm Noncorporate Business). The nonfarm noncorporate business sector comprises partnerships and limited liability companies, sole proprietorships and individuals who receive rental income. This sector is often thought to be composed of small firms, although some of the partnerships included in the sector are large companies. More importantly for our purpose, firms in the nonfarm noncorporate business sector generally do not have access to capital markets and, to a great extent, rely for their funding on loans from commercial banks and other credit providers and on trade credit from other firms.
} 
the asset converges to $p=\beta /(1-\beta) \alpha y$ in the high state so that ${ }^{11}$

$$
\alpha=\frac{1-\beta}{\beta} \frac{p}{y} .
$$

The ratio $p / y$ was proxied by taking the ratio of households' asset holdings to national income in the case of households, and the ratio of assets to value added in the case of SMEs. ${ }^{12}$ Note that at 20 percent, our estimate of the share of capital in SMEs' value added is smaller than the share of capital income in total GDP (or the value for the exponent of capital that is usually assumed when calibrating a Cobb-Douglas production function), which is closer to 0.3. This may reflect the fact that SMEs are less capital intensive than large corporations, or that a larger share of labor income goes to selfemployed entrepreneurs.

Table 3. Parameter values for US households and SMEs

\begin{tabular}{l|c|c|c|c} 
& $\alpha$ & $\phi$ & $\psi$ & $y_{L}$ \\
\hline US households & $24.5 \%$ & $3.1 \%$ & $307 \%$ & 0.963 \\
US SMEs & $20.0 \%$ & $4.6 \%$ & $197 \%$ & 0.969
\end{tabular}

The two parameters in the collateral constraint, $\psi$ and $\phi$, were calibrated using the information in Table $2 .^{13}$ The value of $\phi$ was estimated by dividing the fall in debt by the fall in asset value between the second quarter of 2008 and the second quarter of 2009. ${ }^{14}$ Abstracting again from the risk of a bust, the ratio of debt to asset value converges to $\psi / p+\phi=\frac{\psi(1-\beta)}{\alpha \beta y}+\phi$, so that

$$
\psi=\frac{\alpha \beta y}{1-\beta}\left(\frac{d}{p}-\phi\right),
$$

where $d / p$ is the ratio of debt to asset value. We proxied $d / p$ by taking the ratio of debt to total assets in the second quarter of 2008 for the two US

\footnotetext{
${ }^{11}$ We verified numerically that the asset price during booms in our model is indeed closely approximated by this formula.

${ }^{12}$ The data for national income and the value added of the noncorporate business sector come from the Bureau of Economic Analysis' NIPA data (annual, 2008).

${ }^{13}$ Although it would not be difficult to adjust those numbers for inflation, this would not change the results if we used the same deflator for assets and liabilities. In addition, the inflation rate was relatively low during this period.

${ }^{14}$ The resulting values for $\phi$ are rather low. We investigate an alternative explanation for this ratio based on a model of long-term debt in section 5.2.
} 
sectors. We then applied formula (23) using the values of $\alpha$ and $\phi$ derived before and $y=1$.

Finally, income was normalized to 1 in the high state and $y_{L}$ was calibrated so as to reproduce the fall in asset value observed in the data in the event of a bust (Table 2). ${ }^{15}$

We also considered the relevant parameter values for the US financial sector. Unfortunately, the US Flow of Funds do not report the same balance sheet data for the financial sector as for households or the nonfinancial business sectors. The evidence presented by Adrian and Shin (2009) and Brunnermeier (2009) suggests however that $\phi$ is much higher in the financial sector than in the rest of the economy. Those authors show that the debt $d$ of highly-leveraged institutions had short maturity and satisfied a margin requirement $d \leq(1-\mu) p$ where $p$ is the market value of the institution's financial assets and $\mu$ is the "margin," i.e., the fraction of asset holdings that is financed by the net worth of the institution. In the financial sector, this margin often amounts to just a few percentage points. Note that the margin requirement can also be expressed in the form of our collateral constraint (3), with $\psi=0$ and $\phi=1-\mu$. If $\phi$ is close to 1 , our model yields multiple equilibria. ${ }^{16}$ This points to the "high- $\phi$ " case as perhaps the most relevant one if one wanted to apply our model to the financial sector. This is an interesting direction for future research but we focus here on the "low- $\phi$ " case, which ensures equilibrium uniqueness and makes the model more applicable to the real sector.

\subsection{Results}

Figure 2 shows the policy functions $c(m), p(m)$ and $\lambda(m)$ in the laissez-faire equilibrium, for the benchmark calibration in Table 1 , which represents the SME sector. The equilibrium is unconstrained if and only if wealth is larger

\footnotetext{
${ }^{15}$ The price of real estate is determined, in our model, by $y_{t}$, which could be interpreted as rental income or as the nonpecuniary utility of home ownership. The latter is not observable and the former did not fall by enough in the recent crisis to explain a 30 percent fall in real estate prices. The recent boom-bust in US real estate may have been to some extent the result of a bubble, which our model does not capture as it does not entail any deviation of the asset price from its fundamental value (conditional on the frictions).

${ }^{16}$ Multiple equilibria would perhaps not be a problem in normal times when the financial assets are liquid and can be sold at no or little discount to outsiders, but multiplicity would arise when financial assets loose their liquidity.
} 


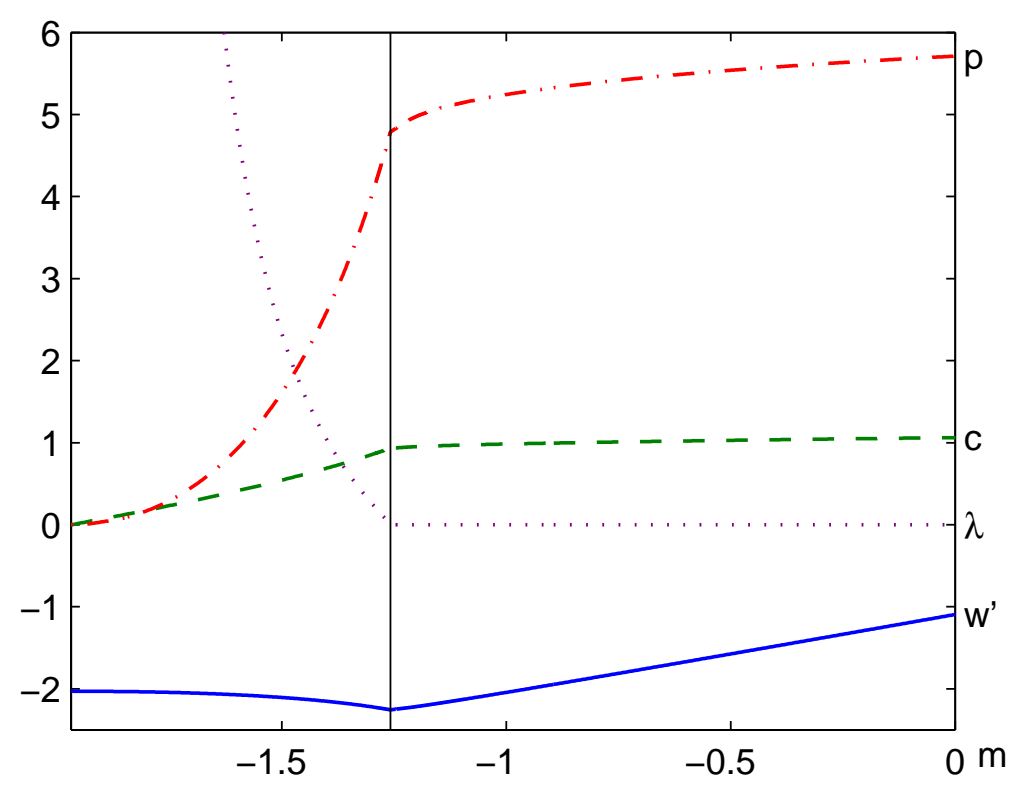

Figure 2: Policy functions $c(m), p(m)$ and $\lambda(m)$.

than $\bar{m}=-1.26$. In the unconstrained region, consumption, saving and the price of the asset are all increasing with wealth. Higher wealth raises current consumption relative to future consumption, which bids up the price of the asset.

The levels of consumption and of the asset price vary more steeply with wealth in the constrained region than in the unconstrained region, reflecting the collateral multiplier. Both consumption and the asset price fall to zero when wealth is equal to $-\psi=-1.97$. By contrast, saving $w^{\prime}$ decreases with wealth in the constrained region. Higher wealth is associated with an increase in the price of collateral, which relaxes the borrowing constraint on insiders and allows them to roll over larger debts.

Figure 3 shows how saving depends on the level of wealth, $w^{\prime}(w)$, for the two states $y=y_{L}, y_{H}$. One can obtain the curve for the low state by shifting the curve for the high state to the right by $\Delta y=y_{H}-y_{L}$. The curves intersect the $45^{\circ}$ line in two points, $A_{H}$ and $A_{L}$, which determine the steady state levels of wealth conditional on remaining in each state, respectively denoted by $w_{H}^{S S}$ and $w_{L}^{S S}$. We observe that both $A_{H}$ and $A_{L}$ are on the downwardsloping branches of each curve, which means that insiders borrow to the point where they are financially constrained in both states. Furthermore, insiders 


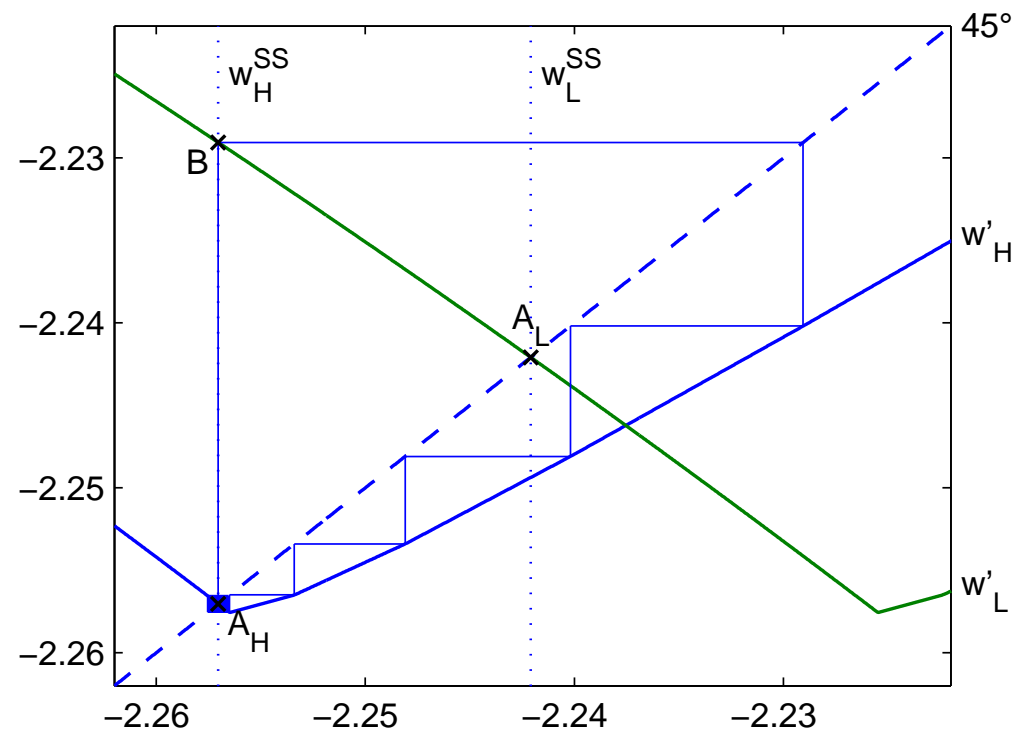

Figure 3: Wealth dynamics

tend to borrow more in the high steady state than in the low steady state $\left(w_{H}^{S S}<w_{L}^{S S}\right)$, which they can do because the price of the collateral asset is higher.

Figure 3 also shows the dynamics of the economy when the steady state is disturbed by a one-period fall in $y$. At the time of the shock, the economy jumps up from point $A_{H}$ to point $B$, as insiders are forced to reduce their debts by the fall in the price of collateral. ${ }^{17}$ The dynamics are then determined by the saving function in the high state (since we have assumed that the low state lasts only one period). The economy converges back to point $A_{H}$. As it approaches $A_{H}$, wealth follows oscillations of decreasing amplitude. There are oscillations because saving is decreasing with wealth in the constrained regime. There is convergence because the slope of the saving curve is larger than -1 in point $A_{H}$ for our benchmark calibration. This is not true for any calibration and the equilibrium can exhibit cyclic or chaotic dynamics if $\phi$ is larger.

Figure 4 shows how the social planner (dashed line) increases saving relative to laissez-faire (solid line). The social planner saves more, implying

\footnotetext{
${ }^{17}$ The price of the collateral asset falls by 12.3 percent, from 4.81 to 4.22 . Thus the borrowing ceiling falls by $\phi \cdot 0.59 \approx 0.03$, which is the distance between $A_{H}$ and $B$.
} 


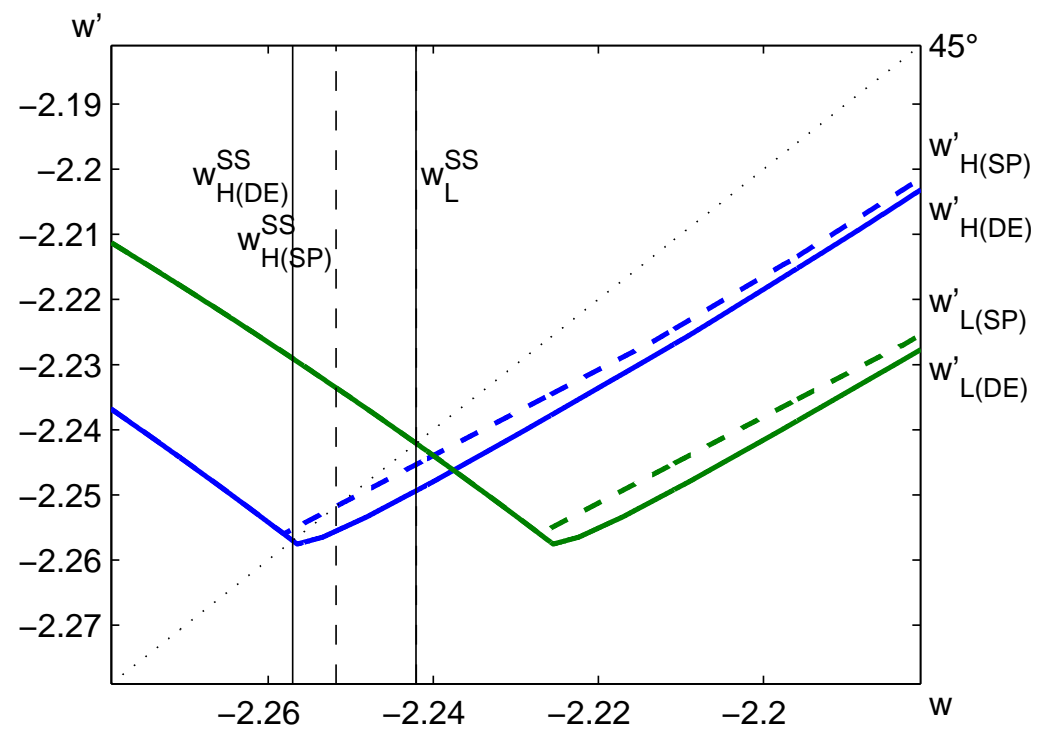

Figure 4: Policy functions of decentralized agents and planner

that the economy has a higher level of wealth and it is no longer financially constrained in the high steady state. The $w^{\prime}(w)$ line is closer to the $45^{\circ}$ line with the social planner, implying that following a one-period fall in $y$, the economy reaccumulates debt at a lower pace than under laissez-faire.

Finally, Figure 5 illustrates the dynamics of the main variables of interest in the social planner equilibrium with a stochastic simulation. The top panel shows how consumption falls at the same time as output when there is a negative shock. Even with the social planner, consumption falls by more than income because of the fall in the price of collateral. Consumption increases above its long-run level in the period after the shock, when the economy is unconstrained and insiders inherit low debt from the credit crunch. The same pattern is observed for the price of the collateral.

The bottom panel shows that the optimal Pigouvian tax rate is positive in the high state and zero in the low state. ${ }^{18}$ Note the countercyclical pattern in the tax rate: it falls in a bust, and does not immediately go back to the longrun level after the bust because the economy temporarily has lower debt. The tax rate increases with the economy's vulnerability to a new credit crunch.

\footnotetext{
${ }^{18}$ We have set the tax to zero when the economy is financially constrained and the tax is not binding.
} 


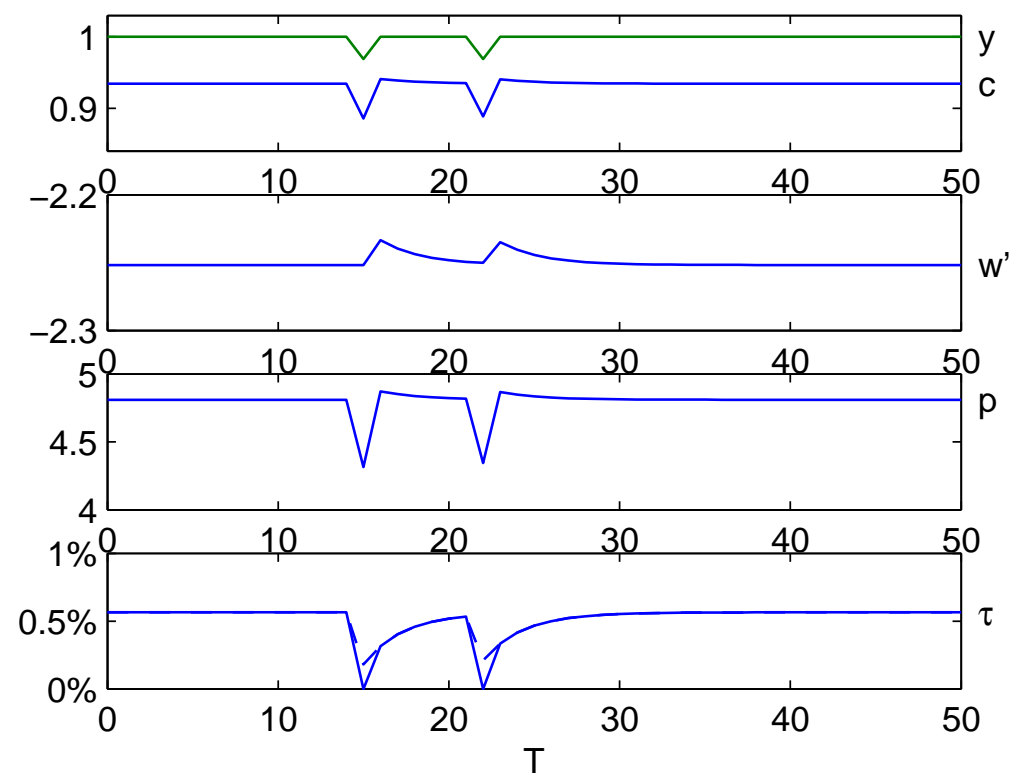

Figure 5: Sample path of $y, c, w^{\prime}, p$ and $\tau$ in the planner's equilibrium

If the optimal tax rate is imposed on insiders, the decline in consumption when the economy experiences a bust is reduced from -6.2 percent to -5.2 percent, and the fall in the asset price during a bust is reduced from -12.3 percent to -10.3 percent.

If we calibrate our model using the parameter values reported in Table 3 for the case of the US household sector, the results are similar to what we found for the SME sector. The optimal magnitude of the macroprudential tax in the high steady state is $\tau_{H}^{S S}=0.48$ percent for households.

\subsection{Sensitivity analysis}

We investigate how the optimal Pigouvian taxation depends on the parameters of the economy. Figure 6 shows how $\tau_{H}^{S S}$ (the steady state rate of tax in the high state) varies with the gross interest rate $R$. For $R=1.04$, the optimal steady-state tax in the economy is close to zero since $\beta R \approx 1$ and insiders accumulate a level of precautionary savings that is sufficient to almost entirely avoid debt deflation in case of busts. ${ }^{19}$

\footnotetext{
${ }^{19}$ Recall that we require $\beta R<1$ for the economy to converge to a stationary equilibrium. If $\beta R \geq 1$, wealth is nonstationary and drifts toward infinity.
} 


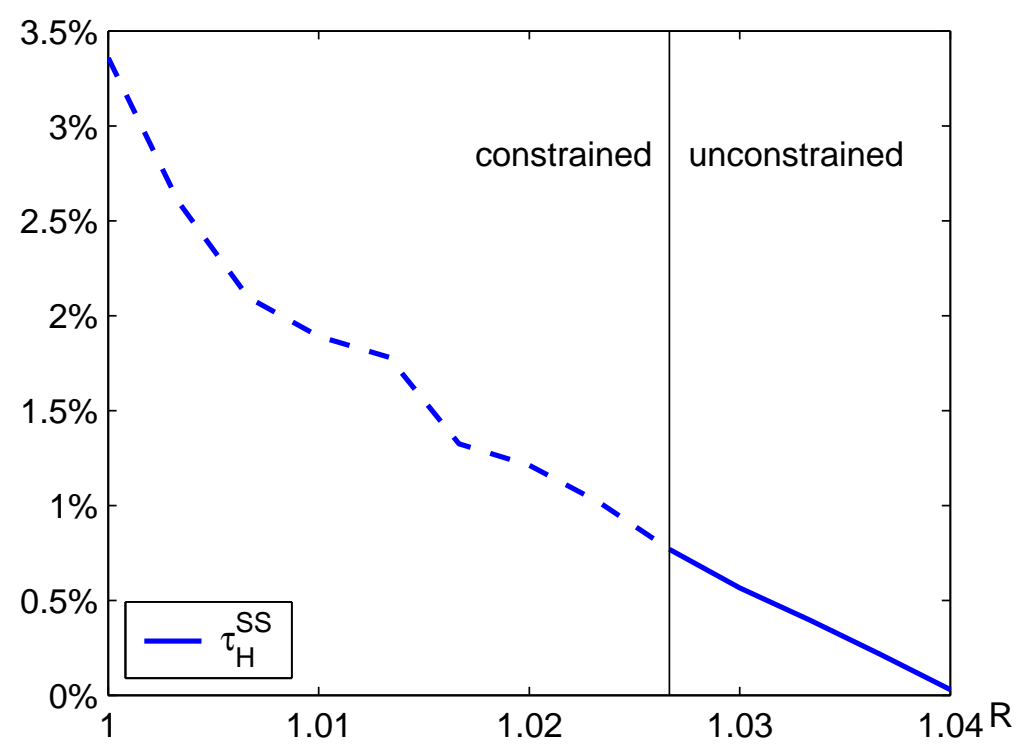

Figure 6: Dependence of macroprudential tax on interest rate

As the interest rate declines, it becomes more attractive for insiders to borrow and the economy becomes more vulnerable to debt deflation in busts. Lower interest rates therefore warrant higher macro-prudential taxation to offset the externalities that individual agents impose on the economy. This effect can be large: the optimal tax rate is multiplied by two when the interest rate is reduced from 2 percent to 1 percent.

For $R \leq 1.026$ (when the line is dashed in Figure 6), the level of debt accumulated by the social planner is high enough that the economy is constrained even in the high steady state $A_{H}$. This means that the social planner could lower the tax rate to zero as soon as the economy becomes constrainedalthough he could also maintain the tax rate at the level shown by the dashed line in Figure 6 or any level in between without changing the equilibrium. In this case, macroprudential taxation matters only in the transition: its role is to slow down the build-up of risk and financial vulnerability after a bust, and thus delay the transition to the constrained regime where the tax no longer matters.

For low levels of $R$, the strong desire of private agents to borrow creates a dilemma for the social planner. On the one hand, it increases the negative externality associated with debt and so the optimal rate of taxation. On 


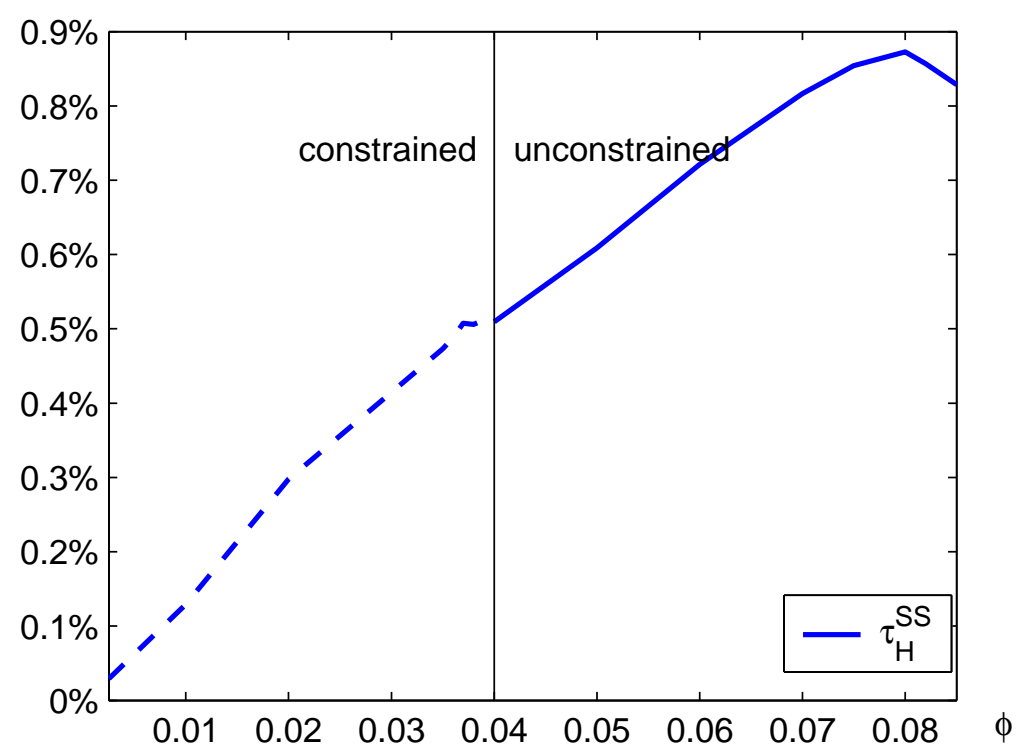

Figure 7: Dependence of macroprudential tax on $\phi$

the other hand, it is also costly in terms of welfare not to let private agents take advantage of the low interest rate by borrowing more. In the context of this tradeoff, the social planner may choose to let the economy go into the constrained regime in booms that lasts long enough, i.e., to let aggregate debt be limited by the constraint rather than by the tax. ${ }^{20}$

Figure 7 depicts the response of the steady-state tax rate $\tau_{H}^{S S}$ to changes in the pledgeability parameter $\phi$. One interpretation for an increase in $\phi$ is a process of financial liberalization or development that enables agents to collateralize a greater fraction of their assets. We observe that the optimal tax rate increases with the ability of private agents to borrow. The more insiders can borrow against their collateral, the greater the potential amplification effects when the borrowing constraint becomes binding. Thus, greater financial liberalization or development warrants tighter macroprudential regulation over a significant part of the parameter space.

The level of financial liberalization/development also determines whether

\footnotetext{
${ }^{20}$ This result echoes a point that has often been made by central bankers in the debate on how monetary policy should respond to asset price booms: that the interest rate increase required to discourage agents from borrowing would have to be so drastic to be effective that it is undesirable (see, e.g., Bernanke, 2002).
} 


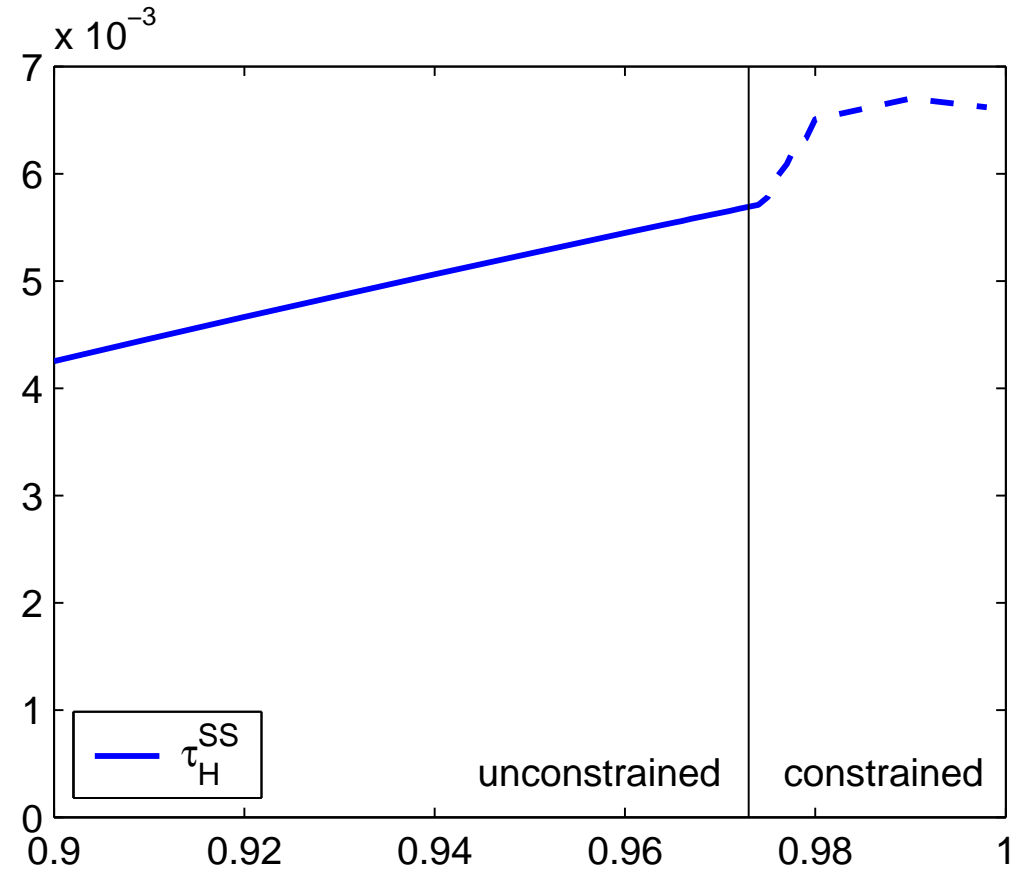

Figure 8: Dependence of macroprudential tax on magnitude of bust $1-y_{L}$

prudential taxation is transitory or permanent. For low levels of $\phi$, we find that the amplification effects are small enough that the planner chooses a constrained equilibrium in steady state and macroprudential taxation is only relevant in the transition from busts to booms. By contrast, if $\phi \geq .037$, the planner implements an unconstrained equilibrium with a Pigouvian tax in steady state. This tax reaches a maximum of almost 1 percent at $\phi=.08$ - for higher values of the parameter the economy becomes so volatile that decentralized agents increase their precautionary savings sufficiently so that the externality declines. ${ }^{21}$

Figures 8 and 9 show how the optimal tax varies with the size and probability of the underlying shock. The optimal tax rate is not very sensitive to those variables: it changes by less than 0.3 percent when the size of the income shock varies between 0 and 10 percent and its probability varies between 0 and 20 percent. The sign of the variation is paradoxical. Figure

\footnotetext{
${ }^{21} \mathrm{As}$ we emphasized in section 3.2 , the economy experiences multiple equilibria for $\phi>0.089$.
} 


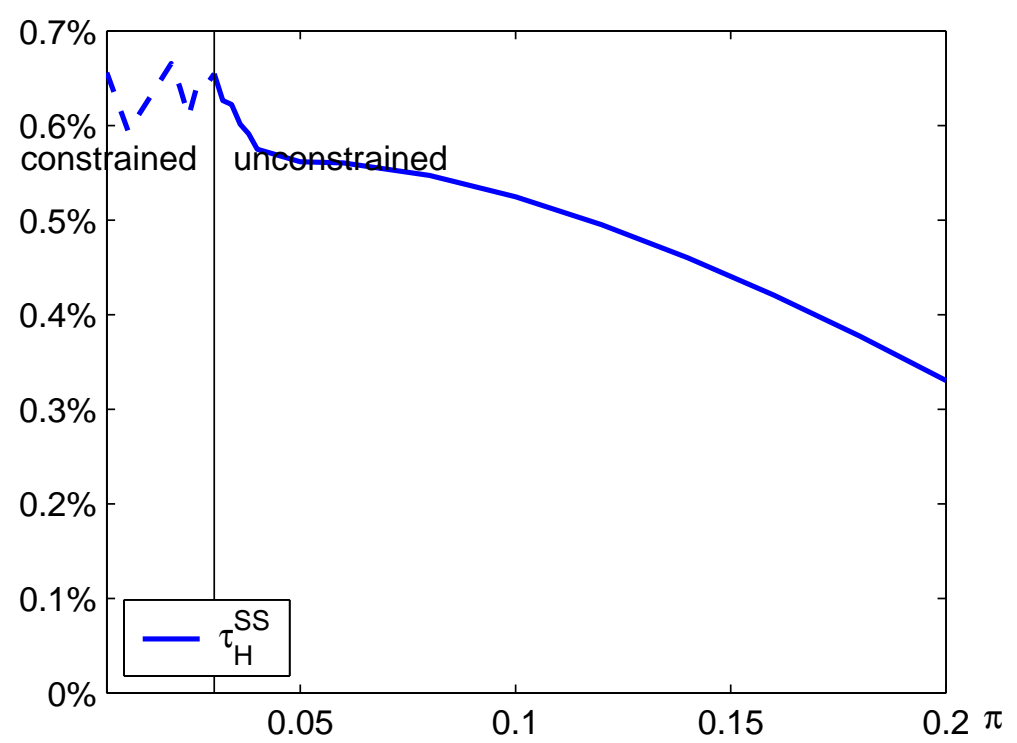

Figure 9: Dependence of macroprudential tax on probability $\pi$ of bust

8 shows that $\tau_{H}^{S S}$ is increasing with $y_{L}$, i.e., the optimal rate of prudential taxation is decreasing with the size of the income shock. This result comes from the endogenous response of precautionary savings by private agents to increased riskiness in the economy. As the size of the shock increases, insiders raise their own precautionary savings, which alleviates the burden on prudential taxation. The tax rate is the highest when the amplitude of the shock is the smallest, but again, these high tax rates do not bind in equilibrium if the income shock is very small (below 2 percent).

We observe a similar pattern for the variation of the optimal tax with the probability of a shock (Figure 9). The optimal tax rate is decreasing with $\pi$ because of the endogenous increase in private precautionary savings. The tax is not binding (and could be set to zero in the long run) if the probability of bust falls below 3 percent. Prudential taxation thus responds the most to "tail risk", i.e., a risk that is realized with a small probability, but not so small that even the social planner can ignore it in the long run. The long-run tax rate is binding and is at its maximum when the probability of shock is between 3 and 5 percent. 


\section{Extensions}

We discuss four extensions of the basic model. In the first one, we assume that the indebted agents are submitted to external financial shocks that abruptly restrict their borrowing constraints. The second and third subsections expand the range of liabilities by assuming that the insiders can issue equity or long-term debt. The last extension looks at whether ex post bailout policies can provide a good alternative to ex ante prudential taxation.

\subsection{Fluctuations in Creditworthiness}

It has been suggested (see e.g. Jermann and Quadrini, 2010) that the recent global financial crisis was driven more by fluctuations in the availability of credit ("financial shocks") than by developments in the real economy ("endowment shocks"). In our framework, the availability of credit is a function of the parameters $\psi$ and $\phi$ in the borrowing constraint. We now assume that the economy may be hit by shocks that reduce $\psi$ rather than $y$.

As in our previous calibration, we choose our parameter values to replicate the declines in credit and asset prices observed during the financial crisis of $2008 / 09$. Income is now deterministic and equal to $y=1$. The parameter $\psi_{H}$ is calibrated so as to reproduce the pre-crisis debt-to-income ratio, and $\psi_{L}$ is calibrated to match the observed fall in the asset price at the time of a bust. This results in a pair of values $\left(\psi_{L}, \psi_{H}\right)=(1.94,1.97)$. The other parameters remain the same as in Table 1.

We solve for the constrained planner's problem in the model with credit shocks and find that the behavior of the model economy is very similar to the case of output shocks. A planner would impose an optimal Pigouvian tax on borrowing of $\tau_{H}^{S S}=0.61$ percent if the economy has reached its steady state during a boom. In a bust, the planner lowers the tax and slowly raises it back to its high steady-state value as the economy re-accumulates debt.

The general magnitude of the externality - and by implication of optimal policy measures targeted at internalizing it - therefore seems to depend not on the source of shocks but on the extent of amplification when the borrowing constraint becomes binding. The optimal policy measures in the economy are similar as long as we calibrate the model in a way that reproduces similar frequencies and magnitudes of crisis as our benchmark model with endowment shocks. 


\subsection{Debt Maturity}

We have observed in the data that outstanding debt fell by substantially less than asset values in the US coporate and household sectors during the financial crisis. This implied a relatively low value of $\phi$ in the calibration. However, the small sensitivity of outstanding debt to collateral value could be due to the fact that a substantial fraction of the debt is medium- or longterm so that the full impact of low collateral values on outstanding debt is observed over several periods. We capture this idea in a tractable way by generalizing the collateral constraint as follows,

$$
\frac{w_{i, t+1}-(1-\delta) w_{i, t}}{R}+\delta\left(\psi+\phi p_{t}\right) \geq 0 .
$$

The parameter $\delta$ represents the fraction of the debt principal that comes due in any given period, i.e., the inverse of the duration of debt. The case of short-term debt corresponds to $\delta=1$, which gives equation (3). In the general case $\delta<1$, the collateral constraint applies only to the flow of new debt issued in period $t$. We interpret $1 / \delta$ as the duration of debt.

Iterating backwards, the new constraint can also be written

$$
\frac{w_{i, t+1}}{R}+\psi+\delta \phi \sum_{s=0}^{+\infty}(1-\delta)^{s} p_{t-s} \geq 0 .
$$

In this formulation, the collateral constraint has the same form as before, except that it involves the weighted average of past collateral prices. In a deterministic steady-state with constant asset price $p_{t}$, the constraint would simplify to our original collateral constraint (3). However, the dynamic behavior of the economy in case of shocks is modified: when the credit constraint binds, a unit decline in the current asset price reduces debt only by a fraction $\delta \phi$ as opposed to $\phi$ in our benchmark model. This mitigates the debt deflation dynamics in the economy.

Figure 10 illustrates how the optimal steady-state tax in the high state $\tau_{S S}^{H}$ varies with debt duration for the parameters of our benchmark calibration as listed in Table $1 .^{22}$ As we increase debt duration by moving leftwards in the graph from $\delta=1$, the debt deflation effects that arise during binding constraints are mitigated. As a result, insiders reduce their precautionary

\footnotetext{
${ }^{22}$ The derivation of the equilibrium with long-term debt and the numerical resolution method are presented in Appendices A.4 and B.2.
} 


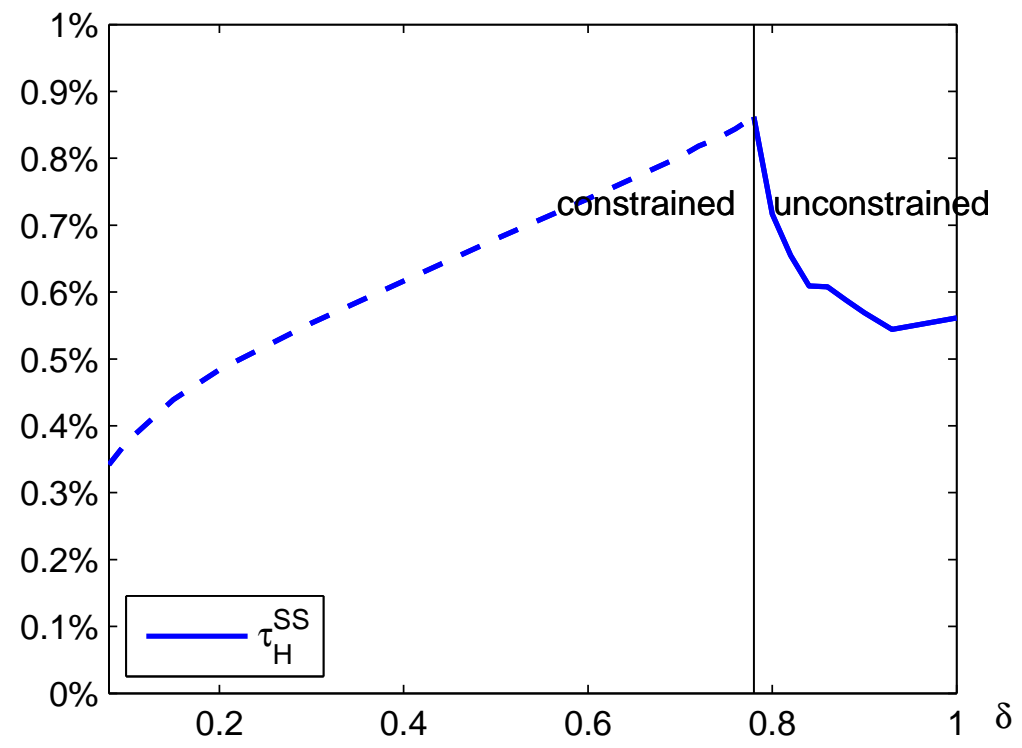

Figure 10: Dependence of macroprudential tax on inverse debt duration $\delta$

savings and the externality of a given dollar of debt at first rises. For $\delta \leq .78$, busts are sufficiently mild that a planner chooses not to insure against binding constraints when the steady state is reached. In this region, a planner uses macroprudential taxation only during the transition from a bust to the next boom in order to slow down the build-up of risk.

An important effect of higher debt duration (lower $\delta$ ) is to make the economy more resilient in the sense of admitting higher values of $\phi$ without leading to multiple equilibria - long-term debt insulates borrowers against self-fulfilling panics. We emphasized earlier that when debt is due yearly $(\delta=1)$, an insider sector with $\phi>\hat{\phi} \approx 9 \%$ was vulnerable to multiple equilibria. As the duration of debt $1 / \delta$ increases, a smaller fraction of debt becomes due in every given period, raising the threshold $\hat{\phi}$ and therefore mitigating the scope for multiple equilibria. This relationship is depicted in figure 11. For example, for $\phi=0.80$ - the typical loan-to-value ratio in the mortgage market - a unique equilibrium is guaranteed as long as $\delta<0.095$, i.e., the duration of debt $1 / \delta$ is greater than 10.6. The duration of a $30-$ year mortgage with a fixed interest rate of $6 \%$ is 11.3 , which satisfies this condition. On the other hand, mortgages with shorter duration, such as teaser loans that are meant to be refinanced sooner because the interest rate 


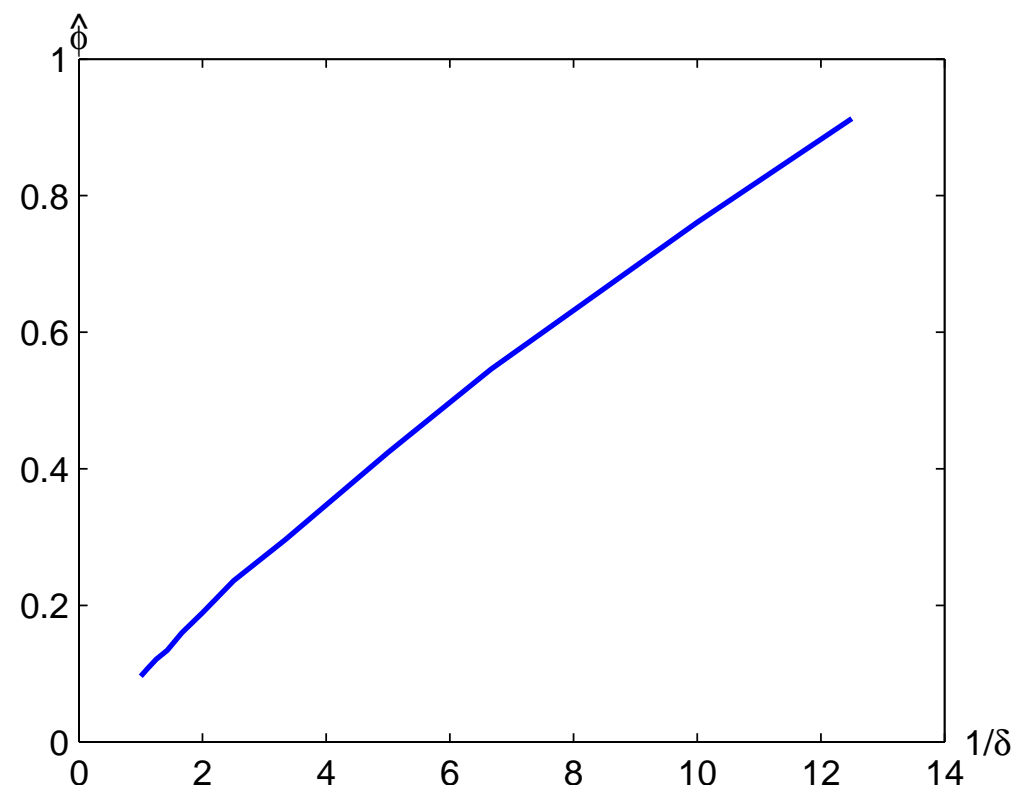

Figure 11: Threshold $\hat{\phi}$ beyond which there are multiple equilibria

is reset to punitive rates, make the equilibrium prone to multiplicity.

\subsection{Outside equity}

We could assume that insiders can sell equity rather than debt. Let us assume that the insider can sell a claim on a share $s_{t} \leq \bar{s}$ of total income to outsiders. This claim will be sold to outsiders at price

$$
\widetilde{p}=\frac{E(y)}{R-1}
$$

and the budget constraint of insiders becomes

$c_{i, t}+a_{i, t+1} p_{t}+\frac{w_{i, t+1}}{R}=(1-\alpha) y_{t}+a_{i, t}\left(p_{t}+\alpha y_{t}\right)+w_{i, t}-s_{i, t} y_{t}+\left(s_{i, t+1}-s_{i, t}\right) \widetilde{p}$.

It is easy to see that the insiders will always sell as much equity as possible, which is a way for them to insure against their income risk (at no cost since outsiders do not require a risk premium on equity) and benefit from the greater patience of outsiders. Thus, $s_{t}=\bar{s}$ in every period. The introduction of equity leads to a consumption boom, but the long-run equilibrium is the 
same as before except that total income is reduced by the factor $(1-\bar{s})$. Our model is homogenous of degree 1 in income $y$, aside from the borrowing constraint. In a sample simulation in which we set $\bar{s}=.5$, we found the optimal macroprudential tax to be $\tau_{H}^{S S}=0.59$, which is very close to the level in our benchmark model (0.56).

Although equity has better risk-sharing properties than debt, it is not used to reduce risk in equilibrium. Insiders issue equity to increase their consumption, leaving them with more liabilities and the same level of debt in the long run. Allowing borrowers to issue equity, thus, does not reduce the need for the prudential taxation of debt.

\subsection{Bailouts}

We have focused on the role of ex ante prudential policies, but real world policy makers also resort to ex post policies, such as bailouts or market interventions to support the price of assets. In our model, the social planner could accumulate a bailout fund financed by a lump-sum tax in booms, which is used to make a transfer to constrained agents in the bust. The budget constraint of private agents becomes

$$
c_{t}+\frac{w_{t+1}}{R}=y_{t}+w_{t}+T_{t},
$$

and that of the social planner can be written,

$$
T_{t}+\frac{b_{t+1}}{R}=b_{t}
$$

where $b_{t}$ is the size of the bailout fund and $T_{t}$ is the lump-sum transfer.

We can show that if this policy does not change the set of periods during which agents are constrained during the boom, it has absolutely no effect on the equilibrium and welfare. This comes from a form of Ricardian equivalence: the agents borrow more and exactly the amount that will leave them the same in the bust as under laissez-faire. This result could be described, loosely speaking, as "moral hazard" (since the agents respond to the bailout insurance by borrowing more) - although this is not moral hazard in the strict sense of the term (there is no hidden action).

To see this more formally, note that by substituting $T_{t}$ from the two equations above one obtains the budget constraint (6) with private wealth $w_{t}$ replaced by total wealth $w_{t}+b_{t}$. Thus, any state-contingent bailout policy 
$b\left(m_{t}\right)$ can be undone by private agents by setting their wealth to $\widetilde{w}\left(m_{t}\right)=$ $w\left(m_{t}\right)-b\left(m_{t}\right)$ where $w\left(m_{t}\right)$ is the laissez-faire policy function. Such a policy satisfies the first-order conditions as well as the constraints if

$$
\frac{w\left(m_{t}\right)-b\left(m_{t}\right)}{R}+\psi+\phi p\left(m_{t}\right) \geq 0,
$$

so that the equilibrium remains the same as laissez-faire in spite of the social planner's intervention.

The inequality above is satisfied if the bailout fund is reduced to zero in the constrained states and is not too large in the unconstrained states. The only way in which such a bailout policy might work is by increasing the size of the bailout fund in booms all the way to the point where private agents can no longer undo the social planner's accumulation because they hit their collateral constraints.

Our bailout irrelevance result is relevant to current policy debates from several perspectives. First, let us discuss the proposal that regulators require banks to pay into an "insurance fund" from which future bailouts are to be financed. If the contribution of each bank is set proportional to its contribution to systemic risk, then such a requirement plays the same role as ex ante prudential taxation in our model. The ex post provision of insurance per se is not relevant since banks can easily undo it by undertaking more risk ex ante. Some authors have argued that capital insurance should be provided by the private sector, for example, through contingent capital requirements (Kashyap, Rajan and Stein, 2008). Our findings suggest that this is only useful if regulators mandate a sufficient level of insurance to make banks internalize their systemic externalities.

Our result is also relevant to the debates on capital controls versus reserve accumulation in dealing with volatile capital flows to emerging market economies. The official conventional wisdom seems to be that countries should respond to a capital inflow first by accumulating precautionary reserves, and with capital controls only as a second line of defense if the first policy is insufficient (Ostry et al, 2010). However, our model suggests that the private sector can easily undo the public accumulation of reserves by borrowing more abroad, and that the accumulation of reserves will have an effect only to the extent that it pushes domestic borrowers against their credit constraints. By contrast, capital controls address the underlying externalities much more directly, and can be differentiated across different types of capital flows to take into account their contribution to systemic risk. 


\section{Conclusion}

This paper has developed a simple model to study the optimal policy responses to booms and busts in credit and asset prices. We found that decentralized agents do not internalize that their borrowing choices in boom times render the economy more vulnerable to credit and asset price busts involving debt deflation in bust times. Therefore their borrowing imposes an externality on the economy. In our baseline calibration, a social planner would impose on average an ex-ante tax of half a percent per dollar on borrowing so as to reduce the debt burden and mitigate the decline in consumption in case of crisis.

The analysis presented in this paper could be extended in several directions. First, it would be interesting to analyze the case where the sensitivity of the credit constraint to the collateral price (parameter $\phi$ ) is large enough to produce multiple equilibria and self-fulfilling asset price busts. This is the relevant case to consider if one wants to apply the model to leveraged financial institutions in systemic liquidity crises. The optimal Pigouvian tax is likely to be higher than with the calibrations that we have considered in this paper, but it is unclear whether the optimal tax should be binding in the long-run steady states. The optimal taxation might be implemented through the kind of countercyclical capital surcharges that are being discussed in the debates about the "macroprudential regulation" of banks. In addition, policies to remove the bad equilibria, such as lending-in-last-resort, may be appropriate.

Another direction of enquiry would take into account the effects of busts in asset prices and credit on production and income. Our model focused on the cost of excessive consumption volatility taking income as exogenous. In the real world, however, busts in credit and asset prices are likely to affect investment and other productive expenditures. It is not obvious a priori that investment will fall below the optimal level in a bust if it is triggered by a negative productivity shock, since in this case the demand for investment will fall at the same time as the credit constraint is tightened. The investment channel, however, might magnify the welfare cost of the fire sale externality in busts, and justify more aggressive prudential taxation in booms.

In addition, asset price and credit busts might have a permanent negative effect on long-run output. The data suggest that output does not generally catch up with its pre-crisis trend following a financial crisis (IMF, 2009). This will be the case, in our model, if the collateral constraint reduces 
productivity-enhancing expenditures. The welfare cost of asset price busts is likely to be larger in this case, leading to larger welfare gains from prudential taxation in booms, and a higher optimal Pigouvian tax level.

Finally, one would like to incorporate money to the model in order to derive insights for the debate on whether and how monetary policy should respond to credit and asset price booms. If there is nominal stickiness, a monetary restriction that raises the real interest rate in the boom should have the same macroprudential effect as the Pigouvian tax discussed in this paper. Such a preemptive restriction may come at a cost for the other objectives of monetary policy (e.g., in terms of inflation), and may not be necessary or desirable if the optimal Pigouvian taxation can be implemented independently of monetary policy. If monetary policy is the only available instrument, however, it stands to reason that it should be used with a prudential purpose in mind, at least at the margin.

\section{References}

Adrian, Tobias and Hyun Song Shin, 2009, "Liquidity and Leverage," manuscript, Department of Economics, Princeton University.

Benigno, Gianluca, Huigang Chen, Christopher Otrok, Alessandro Rebucci and Eric R. Young, 2009, "Optimal Policy with Occasionally Binding Credit Constraints," manuscript, IADB.

Bernanke, Ben S., 2002, “Asset-Price 'Bubbles' and Monetary Policy," remarks before the New York Chapter of the National Association for Business Economics, New York, October 15, 2002.

Bernanke, Ben S., Mark Gertler, and Simon Gilchrist, 1999, "The Financial Accelerator in a Quantitative Business Cycle Framework," Handbook of Macroeconomics, Vol 1C, edited by John B. Taylor and Michael Woodford, Elsevier.

Bianchi, Javier, 2009, "Overborrowing and Systemic Externalities in the Business Cycle," manuscript, Department of Economics, University of Maryland.

Bianchi, Javier, and Enrique Mendoza, 2010, "Overborrowing, Financial Crises, and 'Macroprudential' Taxes", NBER Working Paper 16091. 
Brunnermeier, Markus, 2009, "Deciphering the Liquidity and Credit Crunch," Journal of Economic Perspectives 23(1), 77-100.

Caballero, Ricardo J. and Arvind Krishnamurthy, 2003, "Excessive Dollar Debt: Financial Development and Underinsurance," Journal of Finance $58(2), 867-894$.

Carlstrom, Charles T. and Timothy S. Fuerst, 1997, "Agency Costs, Net Worth, and Business Fluctuations: A Computable General Equilibrium Analysis," American Economic Review 87, 893-910.

Carroll, Christopher D., 2006, "The Method of Endogenous Gridpoints for Solving Dynamic Stochastic Optimization Problems,' Economics Letters, 312-320.

Carroll, Christopher D., 2008, "Theoretical Foundations of Buffer Stock Saving," manuscript, Department of Economics, Johns Hopkins University.

IMF, 2009, "What's the Damage? Medium-Term Output Dynamics After Financial Crises," chapter 4, World Economic Outlook, 121-151.

Jeanne, Olivier and Anton Korinek, 2010, "Excessive Volatility in Capital Flows: A Pigouvian Taxation Approach", American Economic Review, AEA Papers and Proceedings, 403-407.

Jermann, Urban and Vincenzo Quadrini, 2010, "Macroeconomic Effects of Financial Shocks," manuscript, University of Southern California.

Kashyap, Anil K, Raghuram Rajan, and Jeremy C. Stein, 2008, "Rethinking Capital Regulation," in Maintaining Stability in a Changing Financial System, Federal Reserve Bank of Kansas City, 431-471.

Kiyotaki, Nobuhiro and John H. Moore, 1997, "Credit Cycles," Journal of Political Economy 105(2), 211-248.

Korinek, Anton, 2009, "Regulating Capital Flows to Emerging Markets: An Externality View," manuscript, Department of Economics, University of Maryland. 
Korinek, Anton, 2010, "Systemic Risk-Taking: Amplification Effects, Externalities, and Regulatory Responses," manuscript, Department of Economics, University of Maryland.

Lorenzoni, Guido, 2008, "Inefficient Credit Booms," Review of Economic Studies 75(3), 809-833.

Mendoza, Enrique G., 2005, "Real Exchange Rate Volatility and the Price of Nontradables in Sudden-Stop-Prone Economies," NBER Working Paper 11691.

Mendoza, Enrique G., 2010, "Sudden Stops, Financial Crises and Leverage," forthcoming, American Economic Review.

Mendoza, Enrique G. and Katherine Smith, 2006, "Quantitative Implications of a Debt-Deflation Theory of Sudden Stops and Asset Prices," Journal of International Economics 70, 82-114.

Ostry, Jonathan D., Atish R. Gosh, Karl Habermeier, Marcos Chamon, Mahvash S. Qureshi, and Dennis B.S. Reinhardt, 2010, "Capital Inflows: The Role of Controls," IMF Staff Position Note 10/04.

Stokey, Nancy L., Robert E. Lucas and Edward C. Prescott, 1989, Recursive Methods in Economic Dynamics, Harvard University Press.

Zeldes, Stephen P., 1989, "Optimal Consumption with Stochastic Income: Deviations from Certainty Equivalence," Quarterly Journal of Economics 104(2), 275-298. 


\section{A Solution of Benchmark Model}

\section{A.1 Laissez-faire}

Decentralized agents solve the Lagrangian

$$
\begin{aligned}
\mathcal{L}_{t}= & E_{t} \sum_{s=t}^{+\infty} \beta^{t-s}\left\{u\left((1-\alpha) y_{s}+a_{i, s}\left(\alpha y_{s}+p_{s}\right)+w_{i, s}-\frac{w_{i, s+1}}{R}-a_{i, s+1} p_{s}\right)\right. \\
& \left.++\lambda_{i, s}\left[\frac{w_{i, s+1}}{R}+\psi+\phi p_{s}\right]\right\} .
\end{aligned}
$$

Given CRRA utility, this implies the first-order conditions

$$
\begin{array}{rll}
\operatorname{FOC}\left(w_{i, s+1}\right): & c_{i, s}^{-\gamma}=\beta R E_{s}\left[c_{i, s+1}^{-\gamma}\right]+\lambda_{i, s}, \\
F O C\left(k_{i, s+1}\right): & p_{s} c_{i, s}^{-\gamma}=\beta E_{s}\left[c_{i, s+1}^{-\gamma}\left(\alpha y_{s+1}+p_{s+1}\right)\right] .
\end{array}
$$

In a symmetric equilibrium with a representative agent, this gives (4) and $(5)$.

\section{A.2 Deterministic case with $\beta R=1$}

In a steady state with $\beta R=1$, equation (5) implies that the price of the asset is given by (14). The collateral constraint is satisfied if and only if $w / R+\psi+\phi p^{u n c} \geq 0$, that is if wealth is larger than a threshold

$$
m \geq \bar{m} \equiv y-R\left(\psi+\phi p^{u n c}\right) .
$$

A steady state equilibrium exists if and only if $m_{1} \geq \bar{m}$. In this equilibrium, consumption is constant and given by

$$
c^{u n c}\left(m_{1}\right)=\beta y+(1-\beta) m_{1} .
$$

By contrast, if $m_{1}<\bar{m}$, the economy is constrained in period 1. Equation (5) and $u^{\prime}\left(c_{t}\right) \geq u^{\prime}\left(c_{t+1}\right)$ imply $p_{t} \leq p^{u n c}$. Then $w_{2} / R=-\psi-\phi p_{1} \geq$ $-\psi-\phi p^{u n c}$, implies $m_{2}=y+w_{2} \geq \bar{m}$ so that there is an unconstrained steady state equilibrium. We can assume that the economy is in this steady state equilibrium from period 2 onwards and focus on the equilibrium in period 1. 
Using (5) and $p_{2}=p^{u n c}$, the period- 1 price of the asset is given by

$$
p_{1}=\beta\left(\frac{c_{1}}{c_{2}}\right)^{\gamma}\left(\alpha y+p^{u n c}\right)=p^{u n c}\left(\frac{c_{1}}{c_{2}}\right)^{\gamma}
$$

in the constrained regime. Then using $c_{2}=y+r\left(m_{1}-c_{1}\right)$ to substitute out $c_{2}$ gives (15), which can also be written

$$
\widehat{p}\left(m_{1}, c_{1}\right)=p^{u n c} \min \left[r^{-\gamma}\left(\frac{y+r m_{1}}{y+r\left(m_{1}-c_{1}\right)}-1\right)^{\gamma}, 1\right] .
$$

If $\gamma \geq 1$ this is a strictly convex function of $c_{1}$ for $c_{1} \leq c^{u n c}\left(m_{1}\right)$, as shown on Figure 1. Hence the slope of the r.h.s. of (13) reaches its maximum at the kink, which is given by,

$$
\left.\phi \frac{\partial \widehat{p}}{\partial c_{1}}\right|_{c_{1}=c^{u n c}\left(m_{1}\right)}=\phi\left(1+\frac{1}{r}\right) \frac{\gamma \alpha y}{c^{u n c}\left(m_{1}\right)} .
$$

As can be seen on Figure 1, equilibrium multiplicity is possible only if the unconstrained steady state equilibrium exists, which requires $m_{1} \geq \bar{m}$. In addition, equilibrium multiplicity requires the slope of the r.h.s. of (13) to be larger than 1. To avoid multiplicity, it is necessary and sufficient that this slope be smaller than 1 at the kink for $m_{1}=\bar{m}$, that is

$$
\left.\phi \frac{\partial \widehat{p}}{\partial c_{1}}\right|_{c_{1}=c^{u n c}(\bar{m})}<1
$$

If this condition is satisfied, then the slope of the r.h.s. of (13) is lower than 1 everywhere, so that the equilibrium is unique. This is true not only for $m_{1}=\bar{m}$ but also for any $m_{1} \geq \bar{m}$ since the slope at the kink is decreasing in $m_{1}$ (see equation (25)). Conversely, if this condition is not satisfied, then there is multiplicity for $m_{1}$ slightly below $\bar{m}$. Using (25), condition (26) can be rewritten as (16).

\section{A.3 Social planner}

The social planner maximizes the utility of the representative insider subject to the budget constraint (2) and to the credit constraint (18), taking $a_{t}=1$ as given. The Lagrangian of the social planner and his first-order condition on saving are 


$$
\begin{gathered}
\mathcal{L}_{t}^{S P}=E_{t} \sum_{s=t}^{+\infty} \beta^{t-s}\left\{u\left(y_{s}+w_{s}-\frac{w_{s+1}}{R}\right)+\lambda_{s}\left[\psi+\phi \bar{p}\left(y_{s}+w_{s}\right)+\frac{w_{s+1}}{R}\right]\right\} \\
F O C\left(w_{t+1}\right): \quad u^{\prime}\left(c_{t}\right)=\lambda_{t}+\beta R E_{t}\left[u^{\prime}\left(c_{t+1}\right)+\phi \lambda_{t+1} \bar{p}^{\prime}\left(m_{t+1}\right)\right] .
\end{gathered}
$$

If we solve the decentralized agent's problem under a tax that requires the agent to pay $\tau_{t}$ for every dollar borrowed as specified in budget constraint (20), then the first order condition is

$$
F O C\left(w_{t+1}\right): \quad\left(1-\tau_{t}\right) u^{\prime}\left(c_{t}\right)=\lambda_{t}+\beta R E_{t}\left[u^{\prime}\left(c_{t+1}\right)\right] .
$$

This condition replicates the first-order condition of the planner that is given above if the tax rate is set such that

$$
\lambda_{t}+\beta R E_{t}\left[u^{\prime}\left(c_{t+1}\right)+\phi \lambda_{t+1} p^{\prime}\left(m_{t+1}\right)\right]=\lambda_{t}+\beta R E_{t}\left[u^{\prime}\left(c_{t+1}\right)\right]+\tau_{t} u^{\prime}\left(c_{t}\right) .
$$

Simplifying this expression yields the formula (21) given in the text.

\section{A.4 Long-Term Debt}

The Lagrangian of our setup extended to long-term debt that repays a fraction $\delta$ every period is

$$
\begin{aligned}
\mathcal{L}_{t}= & E_{t} \sum_{s=t}^{+\infty} \beta^{t-s}\left\{u\left((1-\alpha) y_{s}+a_{i, s}\left(\alpha y_{s}+p_{s}\right)+w_{i, s}-\frac{w_{i, s+1}}{R}-a_{i, s+1} p_{s}\right)+\right. \\
& \left.+\lambda_{i, s}\left[\frac{w_{i, s+1}-(1-\delta) w_{i, s}}{R}+\delta\left(\psi+\phi p_{s}\right)\right]\right\} .
\end{aligned}
$$

This changes the first-order condition on $w_{s+1}$ to

$$
F O C\left(w_{i, s+1}\right): \quad u^{\prime}\left(c_{i, s}\right)+\beta(1-\delta) E_{s}\left[\lambda_{i, s+1}\right]=\beta R E_{s}\left[u^{\prime}\left(c_{i, s+1}\right)\right]+\lambda_{i, s}
$$

Taking on more debt now not only has the benefit of raising current consumption, but also of having to roll over $(1-\delta)$ less debt next period, which is valuable if the borrowing constraint next period is binding. The remaining first-order conditions are unchanged. 
When including long-term debt, we can no longer summarize the state variables in a single variable $m=w+y$, because $w$ determines the level of debt that comes due in the current period independently of $y$. All policy functions are therefore functions of the pair of state variables $(w, y)$.

The Euler equation of the planner who borrows in long-term debt is

$F O C\left(w_{s+1}\right): \quad u^{\prime}\left(c_{s}\right)+\beta(1-\delta) E_{s}\left[\lambda_{s+1}\right]=\beta R E_{s}\left[u^{\prime}\left(c_{s+1}\right)+\delta \phi \lambda_{s+1} \frac{\partial \bar{p}}{\partial w}\left(w_{s+1}, y_{s+1}\right)\right]+\lambda_{s}$.

\section{B Numerical resolution method}

\section{B.1 Benchmark model}

We present the numerical method in the case where income is i.i.d. and binomially distributed $\left(y=y_{H}\right.$ or $\left.y_{L}\right)$ but the method can easily be extended to the case where $y$ follows a Markov process with more than two states.

We first define a grid $\mathbf{w}$ for wealth. The minimum value in the grid is $w_{\min }=-\psi-y_{L}$. In iteration step $k$, we start with a triplet of functions $c_{k}(m), p_{k}(m)$ and $\lambda_{k}(m)$ where $c_{k}(m)$ and $p_{k}(m)$ are weakly increasing in $m$ and $\lambda_{k}(m)$ is weakly decreasing in $m$. For each $w^{\prime} \in \mathbf{w}$ we associate a quadruplet $(c, p, \lambda, m)$ under the assumption that the equilibrium is unconstrained. We solve the system of optimality conditions from section 3.1 under the assumption that the borrowing constraint is loose, noting that $m^{\prime}=y^{\prime}+w^{\prime}$ :

$$
\begin{aligned}
c^{u n c}\left(w^{\prime}\right) & =\left\{\beta R E\left[c_{k}\left(m^{\prime}\right)^{-\gamma}\right]\right\}^{-\frac{1}{\gamma}}, \\
p^{u n c}\left(w^{\prime}\right) & =\frac{\beta E\left\{c_{k}\left(m^{\prime}\right)^{-\gamma} \cdot\left[\alpha y^{\prime}+p_{k}\left(m^{\prime}\right)\right]\right\}}{c^{u n c}\left(w^{\prime}\right)^{-\gamma}}, \\
\lambda^{u n c}\left(w^{\prime}\right) & =0, \\
m^{u n c}\left(w^{\prime}\right) & =c^{u n c}\left(w^{\prime}\right)+\frac{w^{\prime}}{R} .
\end{aligned}
$$

In the same way, we can solve for the constrained branch of the system for each $w^{\prime} \in \mathbf{w}$ s.t. $w^{\prime} / R \leq-\psi$ under the assumption that the borrowing constraint is binding in the current period as

$$
p^{c o n}\left(w^{\prime}\right)=\frac{-w^{\prime} / R-\psi}{\phi},
$$




$$
\begin{aligned}
c^{c o n}\left(w^{\prime}\right) & =\left[\frac{\beta E\left\{c_{k}\left(m^{\prime}\right)^{-\gamma} \cdot\left[\alpha y^{\prime}+p_{k}\left(m^{\prime}\right)\right]\right\}}{p^{c o n}\left(w^{\prime}\right)}\right]^{-\frac{1}{\gamma}}, \\
\lambda^{c o n}\left(w^{\prime}\right) & =c^{c o n}\left(w^{\prime}\right)^{-\gamma}-\beta R E\left[c_{k}\left(m^{\prime}\right)^{-\gamma}\right] \\
m^{c o n}\left(w^{\prime}\right) & =c^{c o n}\left(w^{\prime}\right)+\frac{w^{\prime}}{R} .
\end{aligned}
$$

We then determine the next period wealth threshold $\bar{w}$ such that the borrowing constraint is marginally binding in the unconstrained system, i.e., such that

$$
\frac{\bar{w}}{R}+\psi+\phi p^{u n c}(\bar{w})=0
$$

This is the lowest possible $w^{\prime}$ that the economy can support (any lower level would violate the collateral constraint). By construction of this threshold, $c^{\text {unc }}(\bar{w})=c^{c o n}(\bar{w})$ for consumption as well as for the other policy variables. This threshold gives the level of $m$ that marks the frontier between the unconstrained and the constrained regimes, $\bar{m}=m^{u n c}(\bar{w})=m^{c o n}(\bar{w})$. The lowest possible level of $m$ is $\underline{m}=m^{\text {con }}(-R \psi)=-\psi$. One can check, using the equations above, that any $w^{\prime} \in[\bar{w},-R \psi]$ can be mapped into one unconstrained quadruplet $\left(c^{u n c}\left(w^{\prime}\right), p^{u n c}\left(w^{\prime}\right), \lambda^{u n c}\left(w^{\prime}\right), m^{u n c}\left(w^{\prime}\right)\right)$ and one constrained quadruplet $\left(c^{c o n}\left(w^{\prime}\right), p^{c o n}\left(w^{\prime}\right), \lambda^{c o n}\left(w^{\prime}\right), m^{c o n}\left(w^{\prime}\right)\right)$.

We can construct the step- $(k+1)$ policy function $c_{k+1}(m)$ for the interval $\underline{m} \leq m<\bar{m}$ by interpolating on the pairs $\left\{\left(c^{c o n}\left(w^{\prime}\right), m^{c o n}\left(w^{\prime}\right)\right)\right\}_{w^{\prime} \in \mathbf{w}}$ where $w^{\prime} \in[\bar{w},-R \psi]$, and then for the interval $m \geq \bar{m}$ by interpolating on the pairs $\left\{\left(c^{\text {unc }}\left(w^{\prime}\right), m^{u n c}\left(w^{\prime}\right)\right)\right\}_{w^{\prime} \in \mathbf{w}}$ for $w^{\prime} \geq \bar{w}$. The resulting consumption function $c_{k+1}(m)$ is again monotonically increasing in $m$. We proceed in the same manner for the policy functions $p_{k+1}(m)$ and $\lambda_{k+1}(m)$, which are, respectively, monotonically increasing and decreasing in $m$. The iteration process is continued until the distance between two successive functions $c_{k}(m)$ and $c_{k+1}(m)$ (or other policy functions) is sufficiently small.

The source code for the program is available at:

http: //www.korinek.com/download/boombust.m

\section{B.2 Model with Long-Term Debt}

When including long-term debt, all policy functions are functions of the pair of state variables $(w, y)$. We present the algorithm to solve for the laissezfaire equilibrium (the case with social planner is similar). We modify the 
procedure outlined above by adjusting one equation in the unconstrained solution

$$
c^{u n c}\left(w^{\prime}, y\right)=\left\{\beta R E\left[c_{k}\left(w^{\prime}, y^{\prime}\right)^{-\gamma}-\beta(1-\delta) \lambda_{k}\left(w^{\prime}, y^{\prime}\right)\right]\right\}^{-\frac{1}{\gamma}},
$$

In the constrained solution, the following four equations have to be satisfied,

$$
\begin{aligned}
p^{c o n}\left(w^{\prime}, y\right) & =-\frac{w^{\prime}-(1-\delta) w^{c o n}\left(w^{\prime}, y\right)}{\delta \phi R}-\frac{\psi}{\phi}, \\
c^{c o n}\left(w^{\prime}, y\right) & =\left[\frac{\beta E\left\{c_{k}\left(w^{\prime}, y^{\prime}\right)^{-\gamma} \cdot\left[\alpha y^{\prime}+p_{k}\left(w^{\prime}, y^{\prime}\right)\right]\right\}}{p^{c o n}\left(w^{\prime}, y\right)}\right]^{-\frac{1}{\gamma}}, \\
\lambda^{c o n}\left(w^{\prime}, y\right) & =c^{c o n}\left(w^{\prime}, y\right)^{-\gamma}+\beta(1-\delta) E\left[\lambda_{k}\left(w^{\prime}, y^{\prime}\right)\right]-\beta R E\left[c_{k}\left(w^{\prime}, y^{\prime}\right)^{-\gamma}\right] \\
m^{c o n}\left(w^{\prime}, y\right) & =c^{c o n}\left(w^{\prime}, y\right)+\frac{w^{\prime}}{R} \text { or } w^{c o n}\left(w^{\prime}, y\right)=c^{c o n}\left(w^{\prime}, y\right)+\frac{w^{\prime}}{R}-y .
\end{aligned}
$$

This is a system of four equations with four unknowns: $p^{\text {con }}\left(w^{\prime}, y\right)$, $c^{c o n}\left(w^{\prime}, y\right), \lambda^{c o n}\left(w^{\prime}, y\right)$ and $w^{c o n}\left(w^{\prime}, y\right)$. It can be solved numerically, and also analytically in the case $\gamma=2$. We substitute $w^{\text {con }}\left(w^{\prime}, y\right)$ from the fourth equation into the first equation to obtain

$$
p^{c o n}\left(w^{\prime}, y\right)=\frac{-\left\{w^{\prime} \cdot \frac{R-1+\delta}{R}-(1-\delta)\left(c^{c o n}\left(w^{\prime}, y\right)-y\right)\right\}-\delta R \psi}{\phi \delta R} .
$$

In combination with the second equation this yields

$$
\left[c^{c o n}\left(w^{\prime}, y\right)\right]^{\gamma}+\frac{-(1-\delta)\left[c^{c o n}\left(w^{\prime}, y\right)\right]+w^{\prime} \cdot \frac{R-1+\delta}{R}+(1-\delta) y+\delta R \psi}{\phi \delta \beta R E\left\{c_{k}\left(w^{\prime}, y^{\prime}\right)^{-\gamma} \cdot\left[\alpha y^{\prime}+p_{k}\left(w^{\prime}, y^{\prime}\right)\right]\right\}}=0 .
$$

For $\gamma=2$, this is a quadratic equation that can be solved as

$$
\begin{aligned}
& c^{c o n}\left(w^{\prime}, y\right)=\frac{1-\delta}{2 \phi \delta \beta R E\left\{c_{k}\left(w^{\prime}, y^{\prime}\right)^{-\gamma} \cdot\left[\alpha y^{\prime}+p_{k}\left(w^{\prime}, y^{\prime}\right)\right]\right\}} \pm \\
& \pm \sqrt{\left(\frac{1-\delta}{2 \phi \delta \beta R E\left\{c_{k}\left(w^{\prime}, y^{\prime}\right)^{-\gamma} \cdot\left[\alpha y^{\prime}+p_{k}\left(w^{\prime}, y^{\prime}\right)\right]\right\}}\right)^{2}-\frac{w^{\prime} \cdot \frac{R-1+\delta}{R}+(1-\delta) y+\delta R \psi}{\phi \delta \beta R E\left\{c_{k}\left(w^{\prime}, y^{\prime}\right)^{-\gamma} \cdot\left[\alpha y^{\prime}+p_{k}\left(w^{\prime}, y^{\prime}\right)\right]\right\}}}
\end{aligned}
$$

The equation has a solution if the discriminant is non-negative, or

$$
(1-\delta)^{2} \geq \phi \delta \beta R\left[w^{\prime} \cdot \frac{R-1+\delta}{R}+(1-\delta) y+\delta R \psi\right] \cdot E\left\{c_{k}\left(w^{\prime}, y^{\prime}\right)^{-\gamma} \cdot\left[\alpha y^{\prime}+p_{k}\left(w^{\prime}, y^{\prime}\right)\right]\right\} .
$$


Note that for $\delta=1$, the solution to the quadratic equation just reduces to the earlier condition

$$
c^{c o n}\left(w^{\prime}, y\right)=\sqrt{-\frac{w^{\prime} / R+\psi}{\phi \beta E\left\{c_{k}\left(w^{\prime}, y^{\prime}\right)^{-\gamma} \cdot\left[\alpha y^{\prime}+p_{k}\left(w^{\prime}, y^{\prime}\right)\right]\right\}}} .
$$

